\title{
Dynamic Agenda Setting
}

\author{
By Ying Chen and Hülya Eraslan*
}

\begin{abstract}
A party in power can address a limited number of issues. What issues to address-the party's agenda-has dynamic implications because it affects what issues will be addressed in the future. We analyze a model in which the incumbent addresses one issue among many and the remaining issues roll over to the next period. We show that no strategic manipulation arises without checks and balances and identify strategic manipulations in the forms of waiting for the moment, seizing the moment, steering, and preemption with checks and balances depending on how power fluctuates. We also discuss efficiency implications. (JEL C78, D72, D78)
\end{abstract}

\begin{abstract}
I egislation is not only about what policies to implement, but also about what priorities to set. Time is limited: in the United States, for example, each congressional term covers a two-year period during which only a small number of issues can be addressed. Therefore, a party in power must prioritize which issues to address while in office. This raises many questions, for example, which issues are to be prioritized? How does the agenda depend on the strength of political power of the incumbent, the political climate, the characteristics of the issues, and the institutional rules?

In this paper, we take a first step towards answering these questions by considering a two-period model with two parties. In each period one of the parties is in power, which we refer to as the incumbent. The incumbent party in each period has the agenda-setting power-it can choose which issue to legislate among many issues (for example, immigration, healthcare, education, or tax reform), but its ability to implement policies on that issue depends on the strength of its power. When it has strong power, it can unilaterally choose the policy; when it has weak power, it can only implement a policy that makes the opposition party no worse off than the status quo. The issues that are not addressed are rolled over to the next period, and
\end{abstract}

\footnotetext{
* Chen: Department of Economics, Johns Hopkins University, Wyman Park Building 544E, 3400 N. Charles Street, Baltimore, MD 21218 (e-mail: ying.chen@jhu.edu); Eraslan: Department of Economics MS-22, Rice University, P.O. Box 1892, Houston, TX 77251 (e-mail: eraslan@ rice.edu). We thank Micael Castanheira, Tiberiu Dragu, Georgy Egorov, Alessandro Lizzeri, César Martinelli, Antonio Merlo, Thomas Palfrey, James Snyder, seminar and conference participants at Boston College, Caltech, Emory University, Michigan State University, National University of Singapore, Rice University, Stony Brook University, University of Southampton, University of York, Priorat Workshop in Bargaining and Politics, V Workshop on Institutions, Individual Behavior and Economic Outcomes, 2014 SITE Workshop on the Dynamics of Collective Decision Making, 2015 CIRPÉE Conference in Political Economy, 2015 Canadian Economic Theory Conference, 2015 Conference on Economic Design, 2015 Wallis Institute Conference, and the referees for helpful comments and suggestions.

Go to https://doi.org/10.1257/mic.20150298 to visit the article page for additional materials and author disclosure statement $(\mathrm{s})$ or to comment in the online discussion forum.
} 
the incumbent party in the second period chooses an issue to legislate among these remaining issues.

To abstract away from the possibility of strategic manipulations in agenda setting due to reelection concerns, we deliberately assume that the power transition is exogenous, that is, the identity of the party in power in the second period and the strength of its power do not depend on the decisions made in the first period. ${ }^{1}$ Although the power transition is exogenous in our setting, the incumbent's strength of power depends on the political institution under which it operates. If the institution has no checks and balances, the incumbent always has strong power, but if the institution has checks and balances, the incumbent may be in strong or weak power.

We identify issues with their status quos and distinguish between controversial and noncontroversial issues. For a controversial issue, the parties would like to move policy in opposite directions, but for a noncontroversial issue, there are policies that both parties prefer to the status quo. Denoting the two parties by $D$ and $R$, we call a noncontroversial issue a Democratic issue when its status quo is so far away from the ideal of party $D$ that party $D$ regards party $R$ 's ideal as an improvement over the status quo. Likewise, we call an issue a Republican issue when its status quo is so far away from the ideal of party $R$ that party $R$ regards party $D$ 's ideal as an improvement over the status quo. The issues differ on how pressing they are: an issue whose status quo yields a lower payoff for a party is more pressing for that party. We focus on partisan preferences in the sense that the most pressing issue for party $D$ is a Democratic issue and the most pressing issue for party $R$ is a Republican issue, but we assume that parties agree which issue is most pressing among the Democratic issues, and which issue is most pressing among the Republican issues.

When there is no power fluctuation, that is, the incumbent in period one retains the same strength of power in the second period, not surprisingly, its optimal dynamic agenda is the same as its optimal static agenda. We also show that when there are no checks and balances, that is, the incumbent in each period is in strong power, no strategic manipulation of agenda arises in equilibrium. When there are checks and balances, however, the incumbent in period one may strategically manipulate its agenda. We identify two kinds of manipulation in agenda setting due to dynamic concerns. To illustrate these manipulations, suppose party $D$ is the incumbent in the first period.

The first kind of manipulation is when party $D$ gives priority to a less pressing Democratic issue. This can benefit party $D$ if party $R$, when it comes in power, addresses the most pressing Democratic issue if it is on the table, but addresses the most pressing Republican issue if the most pressing Democratic issue is no longer on the table. By giving priority to a less pressing Democratic issue and thus leaving the most pressing Democratic issue still on the table, party $D$ directs party $R$ 's agenda towards addressing the most pressing Democratic issue. This is what we call the steering effect.

Even when party $D$ is in power in both periods, giving priority to a less pressing Democratic issue can still be beneficial if party $D$ is in strong power early on but

\footnotetext{
${ }^{1}$ We discuss what happens when we relax this assumption in the concluding remarks.
} 
anticipates to lose its political strength over time. Specifically, party $D$ may take advantage of its strong political power to address a somewhat less pressing issue and implement its ideal policy, knowing that it will be unable to do so when its power diminishes in the future. We call this the seize-the-moment effect. Although addressing a less pressing Democratic issue can be dynamically optimal for the incumbent, it is Pareto inefficient since both parties would be better off if the most pressing Democratic issue is addressed first instead.

Many have found the Obama administration's preoccupation with healthcare reform at a time of economic crisis puzzling. We offer an explanation in terms of strategic agenda setting by regarding the economic crisis as a more pressing Democratic issue and healthcare reform as a less pressing Democratic issue. The Obama administration pushed through the healthcare legislation when the Democratic Party controlled both chambers of Congress. It is plausible that this was partly due to the realization that they would lose the opportunity of reform with weaker power (seize-the-moment effect). Indeed, some of the news coverage explicitly quoted Obama urging the Democrats to seize the moment, and identified a number of factors including the Democratic control of the White House and Congress among the reasons for why the moment had arisen. ${ }^{2}$ Moreover, since the economy is also a pressing issue for the Republicans, the Democrats could still benefit if the Republican Party came in power and addressed the economic issue (the steering effect).

The second kind of manipulation is when party $D$ gives priority to the most pressing Republican issue. This can benefit party $D$ if party $R$, when it comes in power, addresses the most pressing Republican issue if it is still on the table, but addresses the most pressing Democratic issue when the most pressing Republican issue is no longer on the table. Note that if party $R$ addresses a Democratic issue, it implements its ideal independent of its strength of power since party $D$ views party $R$ 's ideal to be an improvement over status quo for a Democratic issue, and party $D$ benefits. By contrast, if party $R$ addresses a Republican issue, it either implements its ideal or it implements a policy that makes party $D$ just as well off as the status quo. If the most pressing Republican issue has a status quo that is close to party $D$ 's ideal, party $D$ does not gain when party $R$ addresses a Republican issue, and therefore it has an incentive to give priority to a Republican issue to prevent party $R$ from addressing it. This is what we call the preemptive effect.

We can interpret the "triangulation" strategy used by the Clinton administration to tackle crime, a longstanding Republican issue, as an example of preemptive agenda setting. The term is due to the political consultant Dick Morris who was an advisor to Bill Clinton. According to Morris (2002), "the essence of triangulation is to use your party's solutions to solve the other side's problems. Use your tools to fix their car." Indeed, the crime bill addressed a traditionally Republican issue but introduced certain progressive policies, for example, crime prevention programs and a ban on assault weapons. Arguably, these had preemptive effects on the Republicans and prevented them from implementing more drastic policies. In our model, such

\footnotetext{
${ }^{2}$ See, for example, "On Health Care, Obama Tries to Seize the Moment," New York Times, June 18, 2009.
} 
preemptive agenda setting happens only when the incumbent expects to lose power in the future. When the crime issue was tackled, the Democrats controlled both the Congress and the presidency, but during the midterm elections of 1994, the Democrats lost both chambers of Congress to the Republicans.

Another possible reason for party $D$ to give priority to a Republican issue is that by postponing the most pressing Democratic issue, party $D$ may be able to implement a better policy on that issue later on. This happens when party $D$ is in weak power early on but anticipates to gain in political strength in the future. We call this the wait-for-the-moment effect, a counter-point of the seize-the-moment effect.

Since strategic manipulations of agenda arise only under a power regime that has checks and balances and some of these manipulations lead to inefficiency, our results point to a tradeoff of having checks and balances in a political system.

Related Literature.-The power of agenda control has long been recognized in the context of choosing among different alternatives on a single issue (see, for example, the seminal papers on monopoly agenda setting by Romer and Rosenthal 1978, 1979). Many papers have shown that the order in which alternatives are pitted against each other affects the voting outcome (see, for example, Black 1958, McKelvey 1976, Plott and Levine 1978, Banks 1985, amd Barberà and Gerber 2017). In our model, there are multiple issues instead of a single issue on which the players can legislate, and the power of agenda control comes from ordering the sequence of issues rather than ordering the sequence of alternatives. An important aspect of our model is capacity constraint and scarcity of legislative time, and in that sense, it is related to Duggan and Martinelli (2011) and Čopič and Katz (2012). As in our model, Duggan and Martinelli (2011) look at the selection of an issue among multiple issues under a capacity constraint but in the context of media reporting. Copič and Katz (2012) consider a model of legislative bargaining over distributive policies in which each legislator can make a proposal, but because of limited capacity, only the one chosen by the agenda setter can be voted on. Unlike our model, there is only one issue in their model. A strand of literature analyzes bargaining over multiple issues, but the emphasis has mostly been on comparing the case when players bargain over the issues separately and the case when they bundle them together (see, for example, Fershtman 1990, Inderst 2000, Lang and Rosenthal 2001, Chen 2002, Jackson and Moselle 2002, In and Serrano 2004, and Chen and Eraslan 2013, 2014). Similar to our paper, Anton and Yao (2012) also consider a dynamic setting, but they focus on the effect of delaying an issue on the allocation of influence activity in the future.

Our paper is also related to studies on the effect of issue selection on election outcomes. Dellis (2009) shows that politicians may manipulate policies in order to influence the set of issues that is decisive in future elections; Egorov (2012); Aragonès, Castanheira, and Giani (2015); and Dragu and Fan (2016) study issue selection in political campaigns. Our paper complements these studies since they consider what issues candidates choose to focus on in order to get elected, whereas we analyze what issues parties choose to address to affect future agenda.

Agenda setting is also an important area of research in communication theory, but the focus is on the ability of news media to influence the salience of topics 
on the public agenda (an early study is McCombs and Shaw 1972). As can been seen, "agenda setting" has different meanings in different contexts. Since we use the phrase to refer to setting priorities in policymaking, our paper shares the same interest with the seminal book by Kingdon (1984), which is a descriptive study drawn from interviews, case studies, government documents, party platforms, press coverage, and public opinion surveys, but does not provide formal analysis.

We describe our model in Section I and then provide examples in Section II to illustrate the strategic manipulations that can arise due to dynamic concerns. We discuss two benchmarks-Pareto efficient outcomes and dictatorship outcomes-in Section III. We divide our analysis of the dynamic agenda-setting game into the period 2 problem (Section IV) and the period 1 problem (Section V) and provide some discussion on extensions of our model in Section VI.

\section{The Model}

There are two parties $D$ and $R$ and two periods. In each period $t=1,2$, one of the parties is in power, and we refer to this party as the incumbent. The incumbent in a given period has the agenda-setting right to choose which issue to legislate among many. In period 1, any issue can be legislated, and in period 2, any issue other than the one legislated in period 1 can be legislated.

The status quo of an issue is in $\mathbb{R}$. We assume that party $D$ 's ideal policy on each issue is $D \in \mathbb{R}$, and party $R$ 's ideal policy on each issue is $R \in \mathbb{R}$ with $R>D$. At the beginning of period 1, there are $n_{R}$ issues with status quos to the left of $D, n_{C}$ issues with status quos between $D$ and $R$, and $n_{D}$ issues with status quos to the right of $R$. The total number of issues is $N=n_{R}+n_{C}+n_{D}$. We assume that the set of issues is sufficiently rich in the sense that there are at least two issues with status quos to the left of $D$ and at least two issues with status quos to the right of $R$ at the beginning of period 1 , that is, $n_{D} \geq 2$ and $n_{R} \geq 2$. From now on, we identify an issue in a given period with its status quo for ease of exposition. We avoid identifying an issue with its status quo across periods, because once an issue is addressed, its status quo changes.

The stage utility for party $i \in\{D, R\}$ from the policies implemented at time $t$ is additively separable across issues and each party has the same payoff function on each issue. Let $z_{k t}$ denote the policy implemented for issue $k$ at time $t$, and let $\mathbf{z}_{t}=\left(z_{1 t}, \ldots, z_{N t}\right)$. The stage utility of party $i$ at time $t$ is given by

$$
u_{i}\left(\mathbf{z}_{t}\right)=\sum_{k=1}^{N} v_{i}\left(z_{k t}\right) .
$$

The dynamic utility for party $i$ is the sum of the stage utilities $u_{i}\left(\mathbf{z}_{1}\right)+u_{i}\left(\mathbf{z}_{2}\right)$. Suppose in period 1 , an issue with status quo $s_{1}$ is addressed and the policy implemented is $x$, and in period 2, an issue with status quo $s_{2}$ is addressed and the policy implemented is $y$. Then, the gain in payoff in period 1 for party $i$ is $v_{i}(x)-v_{i}\left(s_{1}\right)$, and the gain in payoff in period 2 for party $i$ is $v_{i}(x)-v_{i}\left(s_{1}\right)+v_{i}(y)-v_{i}\left(s_{2}\right)$. Therefore, the total gain in payoff for party $i$ is $2\left[v_{i}(x)-v_{i}\left(s_{1}\right)\right]+v_{i}(y)-v_{i}\left(s_{2}\right)$. Notice that once a policy is implemented on an issue, then it is persistent, and the 
parties continue to care about the issues that they addressed in the past. This is why when an issue is addressed in period 1, the parties gain in both that period and the next period.

We assume $v_{i}$ is continuous and single-peaked at $i$. We refer to an issue to the left of $D$ as a Republican issue and an issue to the right of $R$ as a Democratic issue. We say that issues between $D$ and $R$ are controversial, and issues outside the $[D, R]$ interval are noncontroversial. For the noncontroversial issues, we use a lower index to indicate a more extreme status quo. That is, we enumerate the issues in period 1 so that

$$
\begin{aligned}
R_{1} & <R_{2}<\cdots<R_{n_{R}}<D \leq C_{1}<\cdots<C_{n_{C}} \leq R \\
& <D_{n_{D}}<\cdots<D_{2}<D_{1} .
\end{aligned}
$$

Note that since $v_{i}$ is single-peaked, a Democratic issue has a status quo that is so bad for party $D$ that it prefers party $R$ 's ideal to the status quo, and a Republican issue has a status quo that is so bad for party $R$ that it prefers party $D$ 's ideal to the status quo. Moreover, we assume the preferences satisfy a single-crossing property. Specifically, for any $x$ and $x^{\prime}$ such that $x^{\prime}>x$, if $v_{D}\left(x^{\prime}\right) \geq v_{D}(x)$, then $v_{R}\left(x^{\prime}\right)$ $>v_{R}(x)$. Many commonly used utility functions, for example, $v_{i}(x)=-(x-i)^{2}$ or $v_{i}(x)=-|x-i|$, satisfy these conditions. We say that issue $s$ is more pressing for party $i$ than issue $s^{\prime}$ if $v_{i}(s)<v_{i}\left(s^{\prime}\right)$. We say that the preferences are partisan if the most pressing issue for party $D$ is a Democratic issue and the most pressing issue for party $R$ is a Republican issue, that is, if $v_{D}\left(D_{1}\right)<v_{D}\left(R_{1}\right)$ and $v_{R}\left(R_{1}\right)<v_{R}\left(D_{1}\right)$. For most of our analysis, we assume that the preferences are partisan. We focus on partisan preferences since they seem plausible, and we discuss what happens under non-partisan preferences in footnote 10.

For a given issue being legislated, how a policy is chosen depends on the political strength of the incumbent party. If the incumbent party is strong, then it unilaterally chooses the policy to implement without any constraint. If it is weak, then it can only implement a policy that makes the out-of-power party no worse off than the status quo. Since there are two parties, there are four possible power states denoted by $S_{D}, S_{R}, W_{D}$, and $W_{R}$. The power state in period $t$ is described by the realization of a random variable $\pi_{t} \in\left\{S_{D}, S_{R}, W_{D}, W_{R}\right\}$. If $\pi_{t}=S_{i}$, party $i$ is in strong power in period $t$; if $\pi_{t}=W_{i}$, party $i$ is in weak power in period $t$. We assume that the distribution of $\pi_{t}$ (referred to as power transition) is exogenously given, but what power states can occur with positive probability depends on the power regime. Specifically, under a power regime with no checks and balances, the incumbent always has full control of the government, and thus $\pi_{t} \in\left\{S_{D}, S_{R}\right\}$ for $t \in\{1,2\}$. Under a power regime with checks and balances, the incumbent can be either strong or weak. We analyze what happens after the initial power state $\pi_{1}$ is realized, and without loss of generality, we assume that party $D$ is the incumbent in the first period. Our analysis allows for uncertainty in the power state in the second period.

If a party is in power, then it decides what issue to address and what policy to implement on that issue. Since the issue not addressed in the first period rolls over 
to the second period, there is a dynamic link between the decisions made in the first period and the feasible actions in the second period. We use the solution concept of subgame perfect equilibrium and we solve the game using backward induction.

Discussion of Assumptions: Our assumption that the incumbent can legislate only one issue in each period is motivated by the fact that legislative time is limited. One may think that addressing an issue on which both parties can benefit should not take up so much time as to block legislation on other issues, but given the complexity of reforms, this may not be the case. For example, welfare reform during the Clinton administration incurred a long political fight that consumed Congress's attention even though the policy was moving towards the Republican's ideal.

We assume that once an issue is addressed, it cannot be addressed again. Although in practice it is possible that an issue addressed previously is brought to the negotiation table again, in general it seems costly to revisit an issue that has already been addressed in the recent past. For example, Glazer and Lohmann (1999) quote Bill Clinton as saying "After I sign my name to this bill, welfare will no longer be a political issue. ... The two parties cannot attack each other over it," right before signing the welfare bill to "end welfare as we know it." We discuss what happens when the parties are allowed to revisit an issue that has been addressed in Section VI. In particular, we consider the implications of an endogenous status quo when we allow the parties to revisit an issue.

We assume that each party's utility is additively separable across dimensions and the utility function on each dimension is the same. These assumptions allow us to reduce this multidimensional problem to a single-dimensional problem and highlight the basic ideas in a simple model. Similar manipulations in agenda setting like those identified in our paper would arise in a multidimensional setting in which the parties' ideals and their payoff functions are different across different dimensions, but the analysis would be significantly more complicated.

As in many political economy models, we assume that the transition probability is independent of the incumbent's policy choice. (See, for example, Persson and Svensson 1989; Tabellini and Alesina 1990; Acemoglu, Golosov, and Tsyvinski 2011; and Callander and Hummel 2014.) We discuss what happens when we relax this assumption in the concluding remarks.

Finally, we focus on the case with no discounting to avoid more notation. If discounting is introduced, our main results would still hold when the parties are sufficiently patient.

\section{Examples}

In this section, we use simple examples to illustrate the potential manipulations in agenda setting due to dynamic concerns. For all the examples, we assume that $D=-1$ and $R=1$ and use figures to illustrate the status quos of the issues, the parties' preferences, and the optimal proposals. In illustrating the optimal proposals, we use functions $d$ and $r: d(x)$ is the optimal proposal that party $R$ makes on an issue with status quo $x$ in a static game when $R$ is in weak power, and $r(x)$ is the optimal proposal that party $D$ makes on an issue with status quo $x$ in a static game when $D$ is 


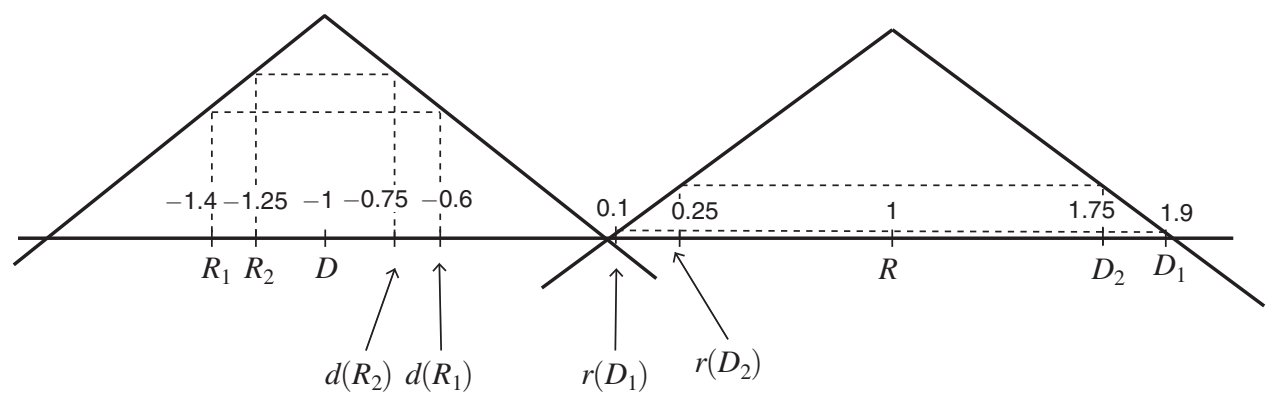

FIgURE 1. EXAMPLE 1

in weak power. (The formal definitions of $d$ and $r$ are in Section IV.) For simplicity, we assume that the power transition is deterministic in the examples, but as we show in the analysis, our results allow for random power transition as well.

Example 1: Party $D$ addresses a less pressing Democratic issue when it is in weak power in period 1 and expects that party $R$ will come in to weak power in period 2 .

Suppose there are two Democratic issues and two Republican issues with $R_{1}=-1.4, R_{2}=-1.25, D_{2}=1.75, D_{1}=1.9$, and $v_{i}(x)=-|x-i|$. These issues together with the parties' preferences are illustrated in Figure 1.

Given that party $D$ needs to make party $R$ at least as well off as the status quo in order to change policy in period 1 , if it addresses issue $D_{1}$, then it can move the policy on $D_{1}$ to 0.1 by making party $R$ just as well off as before. Likewise, if it addresses issue $D_{2}$, then it can move the policy on issue $D_{2}$ to 0.25 by making party $R$ just as well off as before. Since party $D$ can obtain a better compromise by addressing issue $D_{1}$, it is in the short-term interest for party $D$ to address the most pressing Democratic issue $D_{1}$ instead of addressing the less pressing Democratic issue $D_{2}$. But as we show below, with dynamic considerations, party $D$ finds it optimal to roll over the most pressing issue to period 2 to induce party $R$ to address $D_{1}$ in period 2 .

To see this, note that if party $D$ addresses issue $D_{1}$ in period 1 , then party $R$ addresses issue $R_{1}$ in period 2 . This is because party $R$ can move the policy on $R_{1}$ towards its ideal by 0.8 (from -1.4 to -0.6 ) and can move the policy on issue $D_{2}$ towards its ideal by 0.75 (from 1.75 to 1). Given the utility function $v_{R}(x)=-|x-R|$, party $R$ cares about only the distance by which it can move a policy towards its ideal. As a result, party $R$ gains more by addressing $R_{1}$ than by addressing $D_{2}$.

By contrast, if party $D$ addresses issue $D_{2}$ in period 1 , then party $R$ addresses issue $D_{1}$ in period 2 since it can move the policy on $D_{1}$ towards its ideal by 0.9 (from 1.9 to 1 ) whereas it can move policy on $R_{1}$ by only 0.8 (from -1.4 to -0.6 ). Although issue $R_{1}$ is the most pressing issue for party $R$, its ability to move the policy on that issue is limited given its weak power, whereas it can still implement its ideal policy on issue $D_{1}$. Consequently, when issue $D_{1}$ is still on the table, party $R$ finds it optimal to address it even though it is less pressing than issue $R_{1}$.

Given that party $D$ does not gain when party $R$ addresses issue $R_{1}$ (which happens when party $D$ addresses issue $D_{1}$ in the first period) but gains somewhat when party $R$ addresses issue $D_{1}$ (which happens when party $D$ addresses issue $D_{2}$ in the 


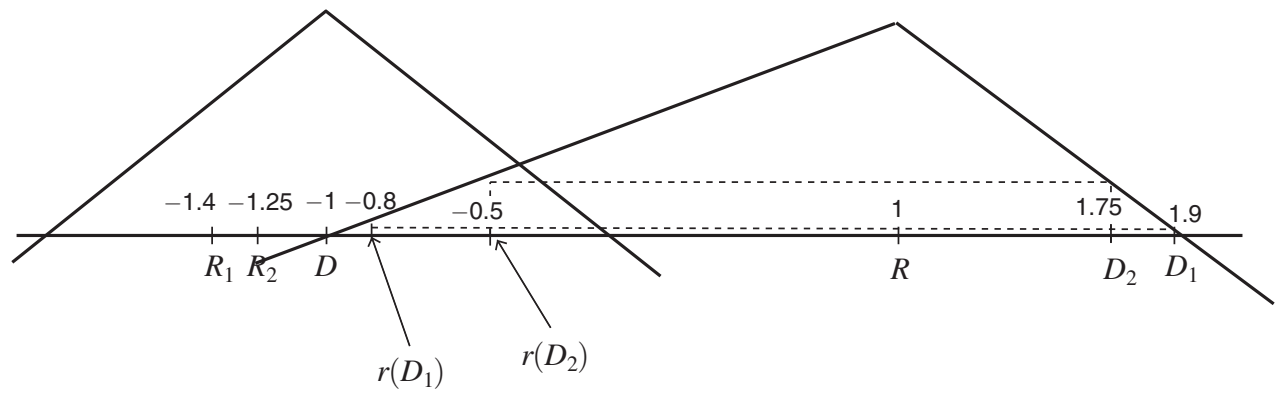

Figure 2. EXAMPLE 2

first period), addressing issue $D_{1}$ instead of addressing issue $D_{2}$ in period 1 involves future cost. It is straightforward to verify that this future cost outweighs the current benefit, ${ }^{3}$ and as a result, party $D$ is better off addressing issue $D_{2}$ in period 1 instead of addressing $D_{1}$.

It is also straightforward to verify that it is not optimal for party $D$ to address a Republican issue in period 1 . Specifically, addressing $R_{1}$ or $R_{2}$ is dominated by addressing $D_{2}$ in period 1 since in either case, party $R$ will address $D_{1}$ in period 2 and the short-term gain from addressing $D_{2}$ is higher for party $D$.

As this example illustrates, a party's dynamic concerns can lead to manipulations in agenda setting in the sense that its optimal dynamic agenda is different from its optimal static agenda. Here, dynamic concerns drive party $D$ to give priority to a less pressing Democratic issue. Intuitively, this is dynamically optimal because party $D$ can steer party $R$ 's agenda towards addressing the most pressing Democratic issue in period 2 when party $R$ comes into power. The equilibrium is inefficient since both parties would have been better off if the most pressing Democratic issue is addressed first.

Example 2: Party $D$ addresses a less pressing Democratic issue when it is in strong power in period 1 but expects to be in weak power in period 2 .

The issues and party $D$ 's preferences are the same as in Example 1. Party $R$ 's preferences are given by $v_{i}(x)=\frac{1}{2}|x-1|$ if $x \leq 1$, and $v_{i}(x)=|x-1|$ if $x \geq 1$. The issues together with the parties' preferences are illustrated in Figure 2.

As in Example 1, it is in the short-term interest for party $D$ to address issue $D_{1}$ in period 1 but its optimal dynamic agenda gives priority to $D_{2}$ in period 1 . To understand the dynamic incentive in this case, first note that if issue $D_{1}$ is rolled over to period 2, then party $D$ addresses issue $D_{1}$ in period 2, but it addresses issue $D_{2}$ in period 2 if $D_{1}$ is already addressed in period $1 .{ }^{4}$ Turning to period 1, regardless of which issue party $D$ addresses in period 1 , it will move the policy on that issue to its ideal since it is in strong power in period 1. It is advantageous for party $D$ to

\footnotetext{
${ }^{3}$ By addressing $D_{1}$ in period 1 , the total gain for party $D$ across the two periods is $1.8 \times 2=3.6$. If party $D$ addresses issue $D_{2}$ in period 1, it can move the policy towards its ideal by 1.5 on that issue (from 1.75 to 0.25 ). In period 2, party $R$ will address issue $D_{1}$ by moving the policy on that issue from 1.9 to its own ideal 1 . Hence, the total gain in payoff for party $D$ across the two periods is $1.5 \times 2+0.9=3.9$, which is higher than 3.6 , the total gain for party $D$ if it addresses issue $D_{1}$ in period 1 .

${ }^{4}$ Since party $D$ is in weak power in period 1, it can move the policy on issue $D_{1}$ towards its ideal by 2.7 (from 1.9 to -0.8 ), on issue $D_{2}$ by 2.25 (from 1.75 to -0.5 ), on $R_{1}$ by 0.4 (from -1.4 to -1 ), and on $R_{2}$ by 0.25 (from -1.25 to -1$)$.
} 


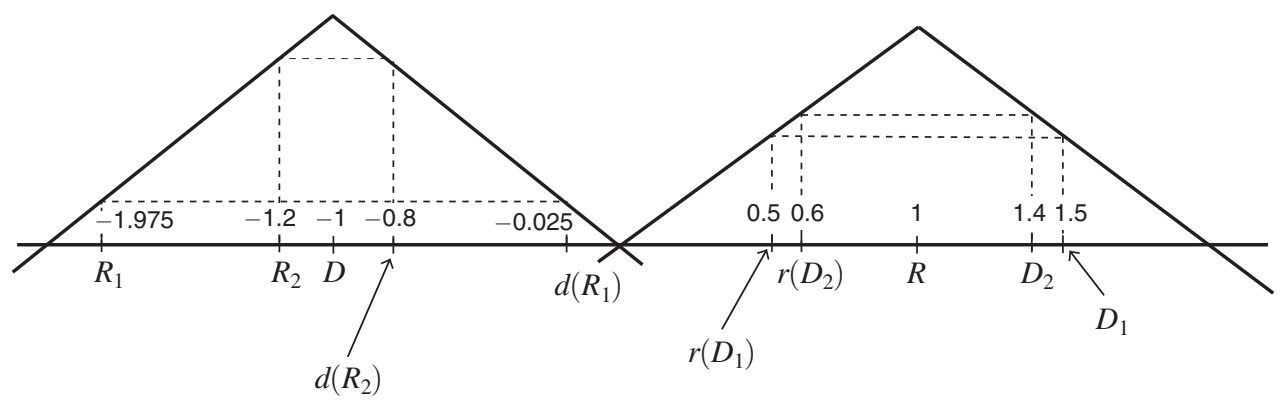

FigURE 3. EXAMPLES 3 AND 4

roll over the more pressing issue $D_{1}$ because it can extract a better compromise on issue $D_{1}$ than on issue $D_{2}$ if it is in weak power in period 2. By addressing the less pressing issue $D_{2}$ when in strong power, party $D$ is able to implement its ideal policy on $D_{2}$ as well as get a better compromise on issue $D_{1}$ when its power weakens in the future. Consequently, party $D$ finds it optimal to address $D_{2}$ in period 1 to take advantage of its strong power. 5 We can think of this as a "seize-the-moment" effect. As in Example 1, the outcome is inefficient.

Example 3: Party $D$ addresses a Republican issue when it is in weak power in period 1 but expects party $R$ to come in to weak power in period 2 .

Suppose there are two Democratic issues and two Republican issues with $R_{1}=-1.975, R_{2}=-1.2, D_{2}=1.4, D_{1}=1.5$, and $v_{i}(x)=-|x-i|$. These issues together with the parties' preferences are illustrated in Figure 3.

It is in the short-term interest for party $D$ to address issue $D_{1}$ since it can move the policy on issue $D_{1}$ towards its ideal by 1 (from 1.5 to 0.5 ) whereas it can move the policy on issue $R_{1}$ towards its ideal by only 0.975 (from -1.975 to -1 ), but we show below that the optimal agenda for party $D$ is to give priority to the Republican issue $R_{1}$.

To see this, note that if issue $R_{1}$ is rolled over to period 1 , then party $R$ finds it optimal to address $R_{1}$ in period 2 , but if issue $R_{1}$ is addressed in period 1 , then party $R$ finds it optimal to address $D_{1}$ in period 2. ${ }^{6}$ Since party $R$ addresses issue $R_{1}$ regardless of what other issue was addressed in period 1 and party $D$ 's period 1 payoff is higher by addressing issue $D_{1}$ instead of $D_{2}$ or $R_{2}$, it follows that addressing issue $D_{1}$ is strictly better than addressing issue $D_{2}$ or $R_{2}$ in period 1 for party $D$. So we only need to compare the choice between issue $D_{1}$ and issue $R_{1}$.

\footnotetext{
${ }^{5}$ If party $D$ addresses issue $D_{1}$ in period 1 , then it can move the policy towards its ideal by 2.9 on that issue (from 1.9 to -1$)$. In this case, it addresses issue $D_{2}$ in period 2 by moving the policy on $D_{2}$ from 1.75 to -0.5 . Hence, the total gain for party $D$ across the two periods is $2 \times 2.9+2.25=8.05$. If party $D$ addresses issue $D_{2}$ in period 1 , then it can move the policy on that issue towards its ideal by 2.75 on that issue (from 1.75 to -1 ). In this case, it addresses issue $D_{1}$ in period 2 by moving the policy on that issue by 2.7 (from 1.9 to ideal -0.8 ). Hence, the total gain in payoff for party $D$ across the two periods is $2.75 \times 2+2.7=8.2$, which is higher than the total gain for party $D$ if it addresses issue $D_{1}$ in period 1 .

${ }^{6}$ When in weak power, party $R$ can move the policy on $R_{1}$ towards its ideal by 1.95 (from -1.975 to -0.025 ), on $R_{2}$ by 0.4 (from -1.2 to -0.8 ), on $D_{1}$ by 0.5 (from 1.5 to 1 ), and on $D_{2}$ by 0.4 (from 1.4 to 1 ).
} 
Given that party $D$ does not gain when party $R$ addresses issue $R_{1}$ (which happens when party $D$ addresses issue $D_{1}$ in the first period) but gains somewhat when party $R$ addresses issue $D_{1}$ (which happens when party $D$ addresses issue $R_{1}$ in the first period), addressing issue $D_{1}$ instead of addressing issue $R_{1}$ in period 1 involves long-term costs. It is straightforward to verify that these future costs outweighs the short term benefits, ${ }^{7}$ and as a result, party $D$ is better off addressing issue $R_{1}$ in period 1 instead of addressing $D_{1}$.

In this example, party $D$ 's dynamic incentive drives it to go against its short-term interest and give priority to a Republican issue. Intuitively, party $D$ preempts party $R$ by giving priority to issue $R_{1}$ since party $D$ does not benefit if party $R$ addresses issue $R_{1}$ but benefits to some degree if party $R$ addresses $D_{1}$. Unlike in the previous example, the equilibrium outcome is still efficient since there is no Pareto improvement.

Example 4: Party $D$ addresses a Republican issue when it is in weak power in period 1 but expects to have strong power in period 2 .

The issues and the parties' preferences are the same as in Example 3. As in Example 3, it is in the short-term interest for party $D$ to address issue $D_{1}$ in period 1 , but its optimal dynamic agenda gives priority to $R_{1}$ in period 1 . To understand the dynamic incentives in this case, first note that regardless of which issue party $D$ addresses in period 2, it will move the policy on that issue to $D$ since it is in strong power in period 2. As such, if issue $D_{1}$ is rolled over to the second period, then party $D$ addresses issue $D_{1}$, and it addresses issue $D_{2}$ in period 2 if $D_{1}$ was already addressed in period 1 . Turning to period 1 , the ability of party $D$ to move the policy on Democratic issues towards its ideal is constrained by the condition that it has to make party $R$ no worse off than the status quo. By contrast, party $D$ can still implement its ideal on a Republican issue even when in weak power. Consequently, party $D$ finds it optimal to address $R_{1}$ in period 1 and postpone addressing $D_{1}$ to period 2 to take advantage of its strong power in period $2 .{ }^{8}$ We can think of this as the "wait-for-the-moment" effect.

\section{Benchmarks}

Dynamically Pareto Efficient Outcomes.-The first benchmark we consider is dynamically Pareto efficient outcomes. These are the outcomes that are Pareto

\footnotetext{
${ }^{7}$ If party $D$ addresses issue $D_{1}$ in period 1 , then it can move the policy towards its ideal by 1 on that issue (from 1.5 to 0.5$)$. In this case, party $R$ addresses issue $R_{1}$ in period 2 by making party $D$ indifferent between the new policy and the status quo. Hence, the total gain for party $D$ across the two periods is $2 \times 1=2$. If party $D$ addresses issue $R_{1}$ in period 1 , then it can move the policy towards its ideal by 0.975 on that issue (from -1.975 to -1 ). In this case, party $R$ addresses issue $D_{1}$ in period 2 by moving the policy on that issue from 1.5 to its own ideal 1 . Hence, the total gain in payoff for party $D$ across the two periods is $0.975 \times 2+0.5=2.45$, which is higher than 2 , the total gain for party $D$ if it addresses issue $D_{1}$ in period 1 .

${ }^{8}$ If party $D$ addresses issue $D_{1}$ in period 1 , then it can move the policy towards its ideal by 1 on that issue (from 1.5 to 0.5$)$. In this case, it addresses issue $D_{2}$ in period 2 by moving the policy on $D_{2}$ from 1.4 to its ideal -1 . Hence, the total gain for party $D$ across the two periods is $2 \times 1+2.4=4.4$. If party $D$ addresses issue $R_{1}$ in period 1 , then it can move the policy towards its ideal by 0.975 on that issue (from -1.975 to -1 ). In this case, it addresses issue $D_{1}$ in period 2 by moving the policy on that issue from 1.5 to its ideal -1 . Hence, the total gain in payoff for party $D$ across the two periods is $0.975 \times 2+2.5=4.45$, which is higher than the total gain for party $D$ if it addresses issue $D_{1}$ in period 1 .
} 
efficient subject to the constraint that the policy on only one issue can be changed in each period. We impose this constraint since parties in the game we consider can change policy on only one issue in each period, so we can think of this as a technological constraint. In the social planner's problem, there are four choice variables: the issue $s_{1}$ addressed in period 1; the policy implemented on the issue addressed in period 1 , denoted by $x$; the issue $s_{2}$ addressed in period 2; and the policy implemented on the issue addressed in period 2, denoted by $y$. Let $S$ denote the set of the issues at the beginning of period 1 , that is, $S=\left\{R_{1}, R_{2}, \ldots, R_{n_{R}}, C_{1}, C_{2}, \ldots, C_{n_{C}}\right.$, $\left.D_{1}, D_{2}, \ldots, D_{n_{D}}\right\}$.

Formally, a dynamically Pareto efficient outcome solves the following social planner's problem:

$$
\max _{s_{1}, x, s_{2}, y} v_{D}(x)+\sum_{s \in S, s \neq s_{1}} v_{D}(s)+\left[v_{D}(x)+v_{D}(y)+\sum_{s \in S, s \neq s_{1}, s_{2}} v_{D}(s)\right]
$$

subject to

$$
v_{R}(x)+\sum_{s \in S, s \neq s_{1}} v_{R}(s)+\left[v_{R}(x)+v_{R}(y)+\sum_{s \in S, s \neq s_{1}, s_{2}} v_{R}(s)\right] \geq \bar{U}
$$

for some $\bar{U}$.

We use the following result to discuss efficiency properties of equilibria. All the proofs are in the Appendix.

PROPOSITION 1: In any dynamically Pareto efficient outcome, if $s$ is more pressing than $s^{\prime}$ for both parties and issue $s^{\prime}$ is addressed, then issue $s$ is addressed in period 1 .

Dictatorship.-We next consider dictatorship. Specifically, suppose party $i$ is the dictator in both periods and it can address one issue in each period. In this case, party $i$ does not face any dynamic trade-off, and therefore its optimal dynamic agenda is the same as its optimal static agenda. Thus, in each period, between issues $s$ and $s^{\prime}$, party $i$ is better off by addressing issue $s$ and implementing its ideal policy on that issue if $v_{i}(s)<v_{i}\left(s^{\prime}\right)$. This implies that the dictator party chooses to address the most pressing issue for itself in each period.

No Power Fluctuation.-Dictatorship is a special case in which there is no power fluctuation. In the next proposition, we show that more generally, in the absence of power fluctuation, the optimal dynamic agenda coincides with the optimal static agenda. All the remaining results describe equilibrium properties.

PROPOSITION 2: If there is no power fluctuation, that is, if $\pi_{2}=\pi_{1}$ with probability 1 , then the incumbent addresses issue $k$ in period 1 only if its period 1 payoff is maximized by addressing issue $k$.

With no checks and balances, the incumbent is always in strong power. In this case, if the incumbent continues to be in power in period 2, then the power state is the same across periods and Proposition 2 implies there is no strategic manipulation 
in the incumbent's agenda. With checks and balances, however, the incumbent can be in either strong or weak power, and even if it continues to be in power in period 2 , the power state may still change, so Proposition 2 no longer applies. Indeed, as illustrated in Examples 2 and 4, with checks and balances, the optimal dynamic agenda may be different from the optimal static agenda even if the incumbent remains the same. In the next section, we analyze what strategic manipulations in agenda setting may arise from dynamic concerns in the presence of power fluctuations in general.

\section{Period 2 Problem}

To facilitate the analysis, we define two functions $d$ and $r$ as follows. For $x \leq D$, let $d(x)=\max \left\{y \leq R: v_{D}(y) \geq v_{D}(x)\right\}$, and for $x \geq R$, let $r(x)=\min \{y \geq D:$ $\left.v_{R}(y) \geq v_{R}(x)\right\}$. Intuitively, $d(x)$ is the optimal policy that party $R$ implements on an issue with status quo $x$ to the left of $D$ when in weak power, and $r(x)$ is the optimal policy that party $D$ implements on an issue with status quo $x$ to the right of $R$ when in weak power. Figures 4 and 5 illustrate these two functions.

The next proposition characterizes the optimal agenda in period 2. For expositional simplicity, we assume that when the incumbent is indifferent between addressing a Republican issue and addressing a Democratic issue, it chooses the agenda that makes the other party better off. Recall that we assume $n_{R} \geq 2$ and $n_{D} \geq 2$ at the beginning of the game, which implies that there is at least one Republican issue and one Democratic issue in period 2.

\section{PROPOSITION 3:}

(i) If the incumbent has strong power in period 2, then it addresses the most pressing issue for itself.

(ii) If the incumbent has weak power in period 2 , then it addresses either issue $s_{R}$ or issue $s_{D}$, where $s_{R}<D$ is the most extreme Republican issue and $s_{D}>R$ is the most extreme Democratic issue. Specifically, if party $D$ is the incumbent, then it addresses issue $s_{R}$ if and only if

$$
v_{D}(D)+v_{D}\left(s_{D}\right) \geq v_{D}\left(s_{R}\right)+v_{D}\left(r\left(s_{D}\right)\right),
$$

and if party $R$ is the incumbent, then it addresses issue $s_{D}$ if and only if

$$
v_{R}(R)+v_{R}\left(s_{R}\right) \geq v_{R}\left(s_{D}\right)+v_{R}\left(d\left(s_{R}\right)\right) .
$$

Proposition 3 implies that the incumbent in period 2 addresses the most pressing issue for one of the parties.

\section{Period 1 Problem}

The next lemma shows that the incumbent in period 1 does not address issues whose status quos are not extreme. Formally, we have the following result. 


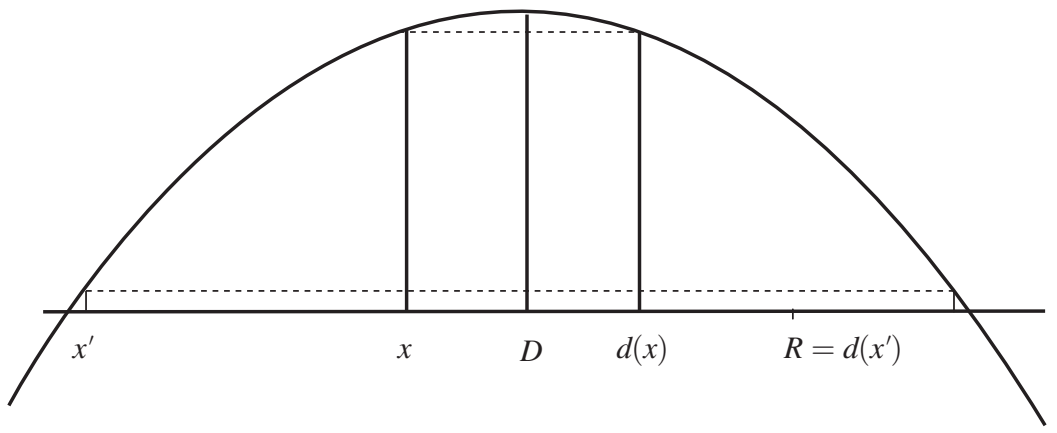

FIGURE 4. $d(\cdot)$



FIGURE 5. $r(\cdot)$

LEMMA 1: The incumbent in period 1 does not address $R_{i}$ or $D_{i}$ with $i \geq 3$, or any controversial issue.

To prove Lemma 1 , we show that addressing issue $R_{2}$ dominates addressing issue $R_{i}$ with $i \geq 3$ for the incumbent in period 1 . This is because addressing issue $R_{2}$ gives the incumbent a strictly higher payoff in period 1 and by Proposition 3 ; the choice of the incumbent in period 2 is the same regardless of whether issue $R_{2}$ or $R_{i}$ was addressed in period 1. A similar argument shows that addressing issue $D_{2}$ dominates addressing issue $D_{i}$ with $i \geq 3$ and addressing any controversial issue is dominated by addressing either $D_{2}$ or $R_{2}$ in period 1 .

Lemma 1 implies that if there are at least two Democratic issues and two Republican issues at the beginning of the game, then it is without loss of generality to consider the agenda-setting problem when there are two Democratic issues and two Republican issues. For the remainder of this section, this is the case that we analyze.

Since controversial issues are not addressed in either period when there are at least two Democratic issues and two Republican issues at the beginning of the game by Lemma 1 and Proposition 3, the payoffs from the controversial issues do not affect the parties' choices. Hence, when we discuss the parties' payoffs in the 
remainder of this section, we omit the payoffs from controversial issues. ${ }^{9}$ We next establish that no matter what the power transition is, party $D$ does not give priority to a less pressing Republican issue.

PROPOSITION 4: Regardless of the power transition, party $D$ does not address $R_{2}$ in period 1 , that is, party $D$ does not give priority to a less pressing Republican issue.

We prove Proposition 4 by showing that addressing the more pressing issue $R_{1}$ instead of issue $R_{2}$ in period 1 gives party $D$ a higher dynamic payoff regardless of the power transition. First, note that regardless of its strength of power in period 1 , if party $D$ addresses a Republican issue, it moves the policy on that issue to its ideal. Hence, party $D$ 's period 1 payoff is higher by addressing issue $R_{1}$ than by addressing issue $R_{2}$. Moreover, similar to the argument for Proposition 2 (which concerns the case when there is no power fluctuation), if party $D$ continues to be in power in period 2, its period 2 payoff is also higher if issue $R_{1}$ instead of issue $R_{2}$ is addressed in period 1 . The interesting case is when party $R$ comes in to power in period 2 , and its choice of agenda varies with what issue has been addressed by party $D$. If party $R$ is in strong power, this arises if issue $R_{1}$ is more pressing than issue $D_{1}$, and issue $D_{1}$ is in turn more pressing than issue $R_{2}$ for party $R$. In this case, by the single-crossing property, party $D$ also finds issue $D_{1}$ more pressing than issue $R_{2}$. Hence, party $D$ is better off if issue $R_{2}$ remains at its status quo (which happens if party $R$ addresses issue $D_{1}$ in period 2) than if issue $D_{1}$ remains at its status quo (which happens if party $R$ addresses issue $R_{1}$ in period 2). It follows that party $D$ is better off in period 2 by addressing issue $R_{1}$ first to induce its rival to address issue $D_{1}$ subsequently than by addressing $R_{2}$ first to induce its rival to address $R_{1}$ subsequently. This implies that if party $R$ is expected to come in strong power in period 2, party $D$ receives a higher dynamic payoff by addressing the more pressing issue $R_{1}$ than $R_{2}$ in period 1. A similar, albeit more involved, argument shows that if party $R$ is expected to come in to weak power in period 2, party $D$ also receives a higher dynamic payoff by addressing the more pressing issue $R_{1}$ than $R_{2}$ in period 1 . Since party $D$ receives a higher dynamic payoff by addressing $R_{1}$ than addressing $R_{2}$ no matter what the power state in period 2 is, it follows that party $D$ does not address $R_{2}$ in period 1 regardless of the power transition, even when there is uncertainty in the power transition.

Does party $D$ ever give priority to a less pressing Democratic issue? As we show in the following subsections, the answer depends on the power transition and the degree of polarization between the two parties. Before we turn to different power transitions, we provide the following lemma, which gives a useful necessary condition for party $D$ to give priority to a less pressing Democratic issue when the

\footnotetext{
${ }^{9}$ When the set of issues is sparse, it is possible that controversial issues are addressed in equilibrium as illustrated by the following example. Suppose party $D$ is in strong power in period 1 and is expected to be in weak power in period 2. Suppose also that there are two issues $R_{1}$ and $C_{1}$ in period 1 with $R_{1}<D<C_{1}<R$. If $v_{D}\left(R_{1}\right)<v_{D}\left(C_{1}\right)$, then it is in the short-term interest for party $D$ to give priority to issue $R_{1}$. However, the optimal dynamic agenda for party $D$ may be to give priority to issue $C_{1}$. Intuitively, since issue $C_{1}$ is controversial, party $D$ addresses it when it has the political power to change the policy on issue $C_{1}$ and postpones tackling issue $R_{1}$. Because the parties have common ground on issue $R_{1}$, it enables party $D$ to implement its ideal even when in weak power.
} 
incumbent's strength of power is the same across periods (that is, either the incumbents are strong in both periods or they are weak in both periods).

LEMMA 2: Suppose the incumbent's strength of power is the same in both periods. If party $D$ addresses issue $D_{2}$ in period 1 , then it must be the case that the probability of party $R$ coming in to power in period 2 is sufficiently high, and that if party $R$ comes in to power in period 2, then it addresses issue $D_{1}$ if $D_{2}$ was addressed in period 1 , and it addresses issue $R_{1}$ if $D_{1}$ was addressed in period 1 .

When the incumbent's strength of power is fixed over time, power fluctuates only when the opposition party comes in to power in period 2. Hence, by Proposition 2, for party $D$ to give priority to the less pressing Democratic issue in period 1 , the probability that party $R$ comes in to power in period 2 must be sufficiently high. Lemma 2 says that it also must be the case that party $D$ 's agenda in period 1 affects the agenda of party $R$ should it come in to power in period 2. Specifically, if the most pressing Democratic issue has been addressed, then party $R$ addresses the most pressing Republican issue, but if the most pressing Democratic issue is still on the table, then party $R$ addresses it.

\section{A. No Checks and Balances}

Consider a power regime without checks and balances. In this case, the incumbent in each period has strong power and can implement its ideal policy on the issue of its choice. Party $D$ 's period 1 payoff is clearly higher if it addresses issue $D_{1}$ than if it addresses issue $D_{2}$. If party $D$ continues to be in power in period 2, then, as shown in Proposition 2, party $D$ is better off by addressing $D_{1}$ than $D_{2}$ in period 1. Furthermore, since $R_{1}$ is the most pressing issue for party $R$, if party $R$ comes in to power in period 2 , it would address $R_{1}$ regardless of whether $D_{1}$ or $D_{2}$ was addressed in period 1. It follows that there is no gain in its period 2 payoff if party $D$ gives priority to issue $D_{2}$, and therefore it does not give priority to $D_{2}$ in period 1 . In the next proposition, we show that party $D$ does not benefit from giving priority to a Republican issue either, implying that it addresses the most pressing Democratic issue $D_{1}$ in period 1 . So without checks and balances, the incumbent's optimal dynamic agenda coincides with its optimal static agenda.

PROPOSITION 5: With no checks and balances, party $D$ addresses issue $D_{1}$ in period 1 .

We give some intuition for why party $D$ does not give priority to a Republican issue when there are no checks and balances. Again, we only need to consider what happens if party $R$ comes in to power in period 2 since party $D$ 's dynamic payoff is higher by addressing issue $D_{1}$ in period 1 in the event that it continues to be in power in period 2. Note that if party $D$ addresses $D_{1}$ in period 1, then party $R$ would address issue $R_{1}$ in period 2 if it comes in to power. In this case, by the end of period 2 , one issue is moved to $D$ 's ideal, another issue is moved to $R$ 's ideal, and issues $D_{2}$ and $R_{2}$ remain unaddressed. If party $D$ addresses $R_{1}$ in period 1 , then party $R$ would 
address either issue $D_{1}$ or issue $R_{2}$ in period 2. Consider first the case when party $R$ addresses issue $D_{1}$ in period 2. In this case too, by the end of period 2, one issue is moved to $D$ 's ideal, another issue is moved to $R$ 's ideal, and issues $D_{2}$ and $R_{2}$ remain unaddressed, implying that party $D$ 's period 2 payoff is the same regardless of whether it addresses issue $D_{1}$ or $R_{1}$ in period 1 . Since party $D$ 's period 1 payoff is higher by addressing $D_{1}$ than addressing $R_{1}$ in period 1 , party $D$ should give priority to issue $D_{1}$. Lastly, consider the case when party $R$ addresses issue $R_{2}$ in period 2 . Note that party $D$ is worse off if party $R$ addresses issue $R_{2}$ than if party $R$ addresses issue $D_{1}$. Therefore, by transitivity, party $D$ does not give priority to issue $R_{1}$ in this case as well. 10

\section{B. Checks and Balances}

With checks and balances, the incumbent in each period can be either weak or strong, and the possibilities of power transition become richer. To compare with the regime without checks and balances, we first consider the case in which the incumbent is always weak.

Weak Incumbent in Both Periods: In contrast to the case in which there are no checks and balances and therefore the incumbent is always in full control, dynamic concerns may drive party $D$ to give priority to a less pressing Democratic issue when the incumbent is weak in each period. To understand the difference, recall that by Lemma 2, if party $D$ addresses $D_{2}$ in period 1, it must be the case that if party $R$ comes in to power in period 2, party $R$ would address $D_{1}$ if it is still on the table but would address $R_{1}$ if $D_{1}$ is no longer on the table. A necessary condition for this is that between issues $D_{1}$ and $R_{1}$, party $R$ prefers to address issue $D_{1}$. Since the most pressing issue for party $R$ is $R_{1}$, this clearly cannot be satisfied if $R$ comes in strong power, but it can still be satisfied if $R$ comes in weak power. This is because when party $R$ is in weak power, the policies that it can implement on a Republican issue is constrained by the opposition party $D$, but party $R$ can still implement its ideal on a Democratic issue, which makes it more attractive for party $R$ to address a Democratic issue when in weak power. Hence, when the incumbent is weak in both periods, party $D$ may affect party $R$ 's agenda in period 2 by giving priority to issue $D_{2}$, and thus leaving $D_{1}$ still on the table. This manipulation is beneficial to party $D$ if the gain in its period 2 payoff more than compensates the loss in its period 1 payoff. We call this the steering effect since the reason for party $D$ to give priority to the less pressing issue $D_{2}$ is that it can then steer party $R$ 's agenda towards addressing $D_{1}$. By Proposition 1, steering is inefficient since both parties would benefit if issue $D_{1}$, which is more pressing for both parties, is addressed in period 1 instead.

\footnotetext{
${ }^{10}$ When preferences are non-partisan, it is possible that party $D$ gives priority to a less pressing Democratic issue. Specifically, if $v_{R}\left(D_{1}\right)<v_{R}\left(R_{1}\right)<v_{R}\left(D_{2}\right), v_{D}\left(D_{2}\right)-v_{D}\left(D_{1}\right)<v_{D}\left(R_{1}\right)-v_{D}\left(D_{2}\right)$, and it is sufficiently likely that party $R$ comes in power in period 2, then party $D$ addresses $D_{2}$ in period 1 . Another interesting case is when the parties have non-partisan preferences and the most pressing issue has a sufficiently bad status quo for both parties. We can think of this as a crisis. For example, if $D_{1}$ is the most pressing issue with a sufficiently bad status quo for both parties, then party $D$ addresses $D_{1}$ even under non-partisan preferences. Not surprisingly, there is no manipulation in agenda setting when the parties face a crisis.
} 
We say that the preferences are strongly partisan if $v_{D}\left(D_{1}\right)+v_{D}(D)<v_{D}\left(R_{1}\right)+$ $v_{D}\left(r\left(D_{1}\right)\right)$ and $v_{R}\left(R_{1}\right)+v_{R}(R)<v_{R}\left(D_{1}\right)+v_{R}\left(d\left(R_{1}\right)\right)$. Note that since $v_{D}(D)$ $\geq v_{D}\left(r\left(D_{1}\right)\right)$ and $v_{R}(R) \geq v_{R}\left(d\left(R_{1}\right)\right)$, strongly partisan preferences imply partisan preferences. If the preferences are strongly partisan, then party $R$ prefers to address issue $R_{1}$ between issues $R_{1}$ and $D_{1}$ even when in weak power, and this implies that party $D$ would not give priority to issue $D_{2}$ in period 1 . One may conjecture that when the incumbent is weak in both periods, if preferences are strongly partisan, then party $D$ always addresses issue $D_{1}$ in period 1, an analog of Proposition 5. But as the next proposition shows, unlike what happens with no checks and balances, party $D$ may still go against its short-term interest and address issue $R_{1}$ instead of $D_{1}$ in period 1 when the incumbent is weak in both periods.

PROPOSITION 6: If the incumbent is weak in both periods,

(i) party $D$ may address $D_{2}$ in period 1 , that is, party $D$ may give priority to a less pressing Democratic issue, but if the preferences are strongly partisan, party $D$ does not give priority to issue $D_{2}$;

(ii) even if the preferences are strongly partisan, party $D$ may still give priority to the Republican issue $R_{1}$ in period 1 .

We have already discussed the steering effect that drives party $D$ to give priority to a less pressing Democratic issue; as to party $D$ giving priority to a Republican issue, we can think of it as preemptive agenda setting. If party $D$ does not address the most pressing Republican issue when in power, then the opposition party will surely address it if it comes in to power in the next period. Since party $D$ typically does not benefit when party $R$ addresses a Republican issue but benefits to some degree if party $R$ addresses a Democratic issue, party $D$ may have the incentive to preemptively tackle the most pressing Republican issue and induce the opposition party to address the most pressing Democratic issue when it comes in power. For preemption to be successful, party $R$ should prefer to address $D_{1}$ between issues $D_{1}$ and $R_{2}$, which is still possible under strongly partisan preferences, provided that the status quo of issue $R_{2}$ is not too far from party $R$ 's ideal. Under strongly partisan preferences, party $D$ 's optimal static agenda is to address $D_{1}$ even when the incumbent is weak in both periods, and therefore giving priority to $R_{1}$ goes against its short-term interest. But unlike the steering effect which is necessarily inefficient, preemption can still be efficient since $R_{1}$ is the most pressing issue for party $R$.

The preemptive effect we identify here is somewhat analogous to the preemptive experimentation in Callander and Hummel (2014). In both models, the party in power goes against its short-term interest in order to prevent more drastic actions by the opposition party in case it comes in to power in the future. However, our paper concerns agenda setting, whereas Callander and Hummel (2014) concerns experimentation in policymaking.

General Power Transitions: With checks and balances, power fluctuations may involve the same party being the incumbent in both periods, but with its strength of 
power changing over time. This gives rise to new dynamic effects in agenda setting, as we show below.

The following proposition shows that the conditions we established for party $D$ to give priority to a less pressing Democratic issue when the incumbent is weak in both periods and to have it ruled out when there are no checks and balances can be extended in the following sense: if the party in power in period 2 is likely to be strong, then party $D$ does not give priority to issue $D_{2}$ (an extension of Proposition 5), but if the party in power in period 2 is likely to be weak, then party $D$ may give priority to issue $D_{2}$ (an extension of Proposition 6, part (i)).

\section{PROPOSITION 7:}

(i) If it is sufficiently likely that the party in power in period 2 is strong, then party $D$ does not give priority to the less pressing Democratic issue $D_{2}$ in period 1 .

(ii) If it is sufficiently likely that the party in power in period 2 is weak, then party $D$ may give priority to the less pressing Democratic issue $D_{2}$ in period 1.

For part (ii), party $D$ may have the incentive to give priority to the less pressing issue $D_{2}$ due to two effects. First, if party $D$ expects to lose power to party $R$, then it may want to roll over the more pressing issue $D_{1}$ to induce $R$ to tackle it in period 2 . This is similar to the steering effect identified when the incumbent is weak in both periods. Second, if party $D$ expects to be still in power, but only weakly, then it may want to roll over the more pressing issue $D_{1}$ to extract a better compromise. This is reminiscent of Romer and Rosenthal (1979), which shows that a monopoly agenda-setter is better off when the status quo is further away from the opponent's ideal. Our result extends Romer and Rosenthal (1979) by providing an implication of their insight in a dynamic multiple-issue setting. Note that unlike the steering effect, the second effect arises only when the same party is still in power in period 2 but with weakened political strength-this is the "seize-the-moment" effect discussed in Example 2.

Another new effect that may arise is when the incumbent is in weak power in period 1 but expects to gain in political strength in the future. As we show in Proposition 8, party $D$ may give priority to a Republican issue against its short-term interest in this case (under strongly partisan preferences, party $D$ 's optimal static agenda is to address issue $D_{1}$ ). The reason here for party $D$ to give priority to a Republican issue is different from the preemptive effect when the incumbent is weak in both periods. Party $D$ benefits from giving priority to a Republican issue here because by postponing the most pressing issue $D_{1}$ until it gains enough political strength, it will be able to implement its ideal policy on that issue. This is the "wait-for-the-moment" effect discussed in Example 4.

PROPOSITION 8: Even if the preferences are strongly partisan, party D may give priority to the Republican issue $R_{1}$ in period 1 if it is in weak power in period 1 but expects to be in strong power in period 2 . 
TABLE 1

\begin{tabular}{|c|c|c|c|c|}
\hline$\pi_{1} \backslash \pi_{2}$ & $S_{D}$ & $S_{R}$ & $W_{D}$ & $W_{R}$ \\
\hline$S_{D}$ & $\begin{array}{l}\text { no power fluctuation } \\
\text { no manipulation }\end{array}$ & $\begin{array}{l}\text { no checks and balances } \\
\text { no manipulation }\end{array}$ & $\begin{array}{l}\text { may give priority to } D_{2} \\
\text { (seize the moment) }\end{array}$ & $\begin{array}{l}\text { may give priority to } D_{2} \\
\text { (steering) }\end{array}$ \\
\hline$W_{D}$ & $\begin{array}{l}\text { may give priority to } R_{1} \\
\text { (wait for the moment) }\end{array}$ & $\begin{array}{l}\text { may give priority to } R_{1} \\
\text { (preemption) }\end{array}$ & $\begin{array}{c}\text { no power fluctuation } \\
\text { no manipulation }\end{array}$ & $\begin{array}{l}\text { may give priority to } D_{2} \text { or } R_{1} \\
\text { (steering or preemption) }\end{array}$ \\
\hline
\end{tabular}

We summarize the results in Table 1. The rows correspond to $\pi_{1}$, the power state in period 1 , and the columns correspond to $\pi_{2}$, the power state in period 2 . The entries describe the possible agenda manipulations under different power transitions and the effects that give rise to them. The table includes only deterministic power transitions; with random power transitions, agenda manipulations may arise from a combination of the different effects, weighted by the probability of the future power state.

\section{Discussion and Concluding Remarks}

Understanding agenda setting in a multi-issue environment with limited capacity is an important research question, but it has received limited attention in the literature. Our analysis has shown the different strategic manipulations that may arise under different power transitions when the agenda formed in an earlier period has dynamic implications. Even though our model is stylized, we view a main contribution of our paper as providing a simple but plausible framework that one can build upon to address further questions about agenda setting. Indeed, there are many interesting directions in which to extend the model, and we discuss some of them here.

Revisiting an Issue: One assumption we have made is that once an issue is addressed, it cannot be addressed again in the next period. In the following example, we illustrate that if an issue addressed earlier is allowed to be revisited, then it creates an endogenous status quo. In this case, in addition to strategic manipulations in agenda setting, an incumbent may implement a policy that is not statically optimal on the issue of its choice.

Example 5: Suppose $D=-1, R=1$, and $v_{i}(x)=-|x-i|$.

For simplicity, suppose that there are only two Democratic issues with $D_{1}=2.5$, $D_{2}=2$; party $D$ is in strong power in period 1 , and party $R$ is in strong power in period 2. If an issue that has been addressed in period 1 cannot be revisited in period 2, then in equilibrium, party $D$ addresses issue $D_{1}$ by moving the policy on that issue to its ideal $D$ in period 1, and party $R$ addresses the remaining issue $D_{2}$ in period 2 by moving the policy on that issue to its ideal $R$.

If an issue that has been addressed in period 1 is allowed to be revisited in period 2 , however, it is no longer optimal for party $D$ to address $D_{1}$ in period 1 . To see this, 
suppose party $D$ addresses $D_{1}$ in period 1 . Note that if it moves the policy on that issue $D_{1}$ to its ideal $D$, then, in period 2, party $R$ will revisit the issue and move the policy to its ideal $R$. In this case, the total gain in payoff for party $D$ is $3.5+1.5=5$. If party $D$ addresses issue $D_{1}$ by moving the policy on that issue to zero instead, then, in period 2, party $R$ will address issue $D_{2}$ by moving the policy on that issue to its ideal $R .{ }^{11}$ In this case, party $D$ 's total gain in payoff is $2.5 \times 2+1=6$. Hence, if party $D$ addresses issue $D_{1}$ in period 1, it is optimal to move the policy on that issue to zero instead of all the way to its ideal $D$ to prevent party $R$ from revisiting the issue in period 2. Similarly, if party $D$ addresses issue $D_{2}$ in period 1, it is optimal to move the policy on that issue to -0.5 instead of all the way to its ideal so that party $R$ does not revisit the issue in period 2 . In this case, party $R$ addresses issue $D_{1}$ in period 2 by moving the policy to its ideal $R=1$. Hence, the total gain in payoff to party $D$ is $2.5 \times 2+1.5=6.5$, which implies that it is better for party $D$ to address issue $D_{2}$. This example shows that when an issue can be revisited, not only does party $D$ give priority to the less pressing issue $D_{2}$, it also implements a policy on that issue which is not statically optimal. In particular, the policy it implements is more moderate than if the issue cannot be revisited. ${ }^{12}$

Endogenous Power Transitions: We have assumed for simplicity that the power transition is exogenous. Many papers in the political economy literature make the same assumption, but one exception is Azzimonti (2011). She assumes that voters care about policies chosen by politicians as well as another dimension unrelated to policies (for example, valence). Since voters are forward looking and the politicians' policy preferences are known, in equilibrium the reelection probabilities are constant in the chosen policies. If we incorporate forward-looking voters in our model, we obtain something similar: the power transition does not depend on the incumbent's chosen agenda and power fluctuation comes from the uncertainty about another dimension independent of the incumbent's choice.

It is possible that voters are not all forward looking or there may be information asymmetries between politicians and voters that lead to retrospective voting. In particular, a party's constituents may punish the party for not addressing the most pressing issue, perhaps because they do not understand the strategic advantage of doing so or they make negative inferences about the politician's type. This will strengthen a party's incentive to address the most pressing issue and dilute its incentive to manipulate the agenda, but the basic insights we obtained in our paper still hold.

Endogenous Number of Issues Addressed: We have considered the stark case in which only one issue can be addressed in a period. Although this approach has provided useful insight into parties' dynamic incentives in setting their agendas, one should think that the number of major issues that are tackled in a political cycle is not

\footnotetext{
${ }^{11}$ We assume that party $R$ addresses issue $D_{2}$ with the status quo at two even though it is indifferent between addressing $D_{2}$ and issue $D_{1}$ whose status quo is at zero in period 2. Without this assumption, party $D$ does not have a best response in period 1 .

${ }^{12}$ The moderation effect on policy through endogenous status quo is reminiscent of Bowen, Chen, and Eraslan (2014). A similar effect also appears in Buisseret and Bernhardt (2015).
} 
fixed. Understanding what determines the scope of a party's agenda, in particular, when a party is able to push an expansive agenda and when it is stuck in gridlock is an interesting and important question.

Longer Time Horizon: The state variable in our model has many dimensions, making the analysis beyond two periods difficult. A full analysis of a model with a longer time horizon is beyond the scope of our paper, but we conjecture that similar effects as those we identify in the paper would arise, but new effects may arise with a longer horizon (for example, an incumbent may choose to address an issue to preempt an anticipated preemption).

Combining Issues: Capacity constraint drives the inefficiency that arises in our paper. While we believe that many important issues are too complex to be dealt with within one legislative cycle, there are ways to alleviate this inefficiency in democratic regimes. For example, one way would be by adding amendments that concern smaller issues to a bill about a larger issue. Another way would be through vote trading over different issues legislated in different cycles. How the practice of logrolling affects agenda setting is an interesting question beyond the scope of our paper.

Issue Ownership: In the United States and other democratic countries, a party may "own" certain issues because it has a reputation of having expertise regarding them and is perceived to be better at handling them than other parties. In our paper, we assume that neither party has an advantage in addressing any particular issue and thus abstract away from issue ownership. There is research on how issue ownership affects campaigning and party rhetoric (see, for example, Petrocik 1996 and Holian 2004), but to the best of our knowledge, there is no paper on how it affects agenda setting. It would be an interesting extension to incorporate issue ownership in our model and see the effect it has on agenda setting. Indeed, Holian (2004) discusses Clinton's rhetoric about stealing the crime issue, an issue traditionally owned by the Republican Party. With idiosyncratic abilities to handle different issues, an incumbent may strategically choose to give priority to an issue with which it is perceived not to be especially good in order to steal the electorate's reason to elect the other party. This suggests that another explanation for Clinton's triangulation strategy (discussed in the context of the preemptive effect in our analysis) is office motivation, which complements the policy motivation we focus on in this paper.

Nonstationary Preferences: In our model, we assume that preferences do not change over time, which rules out the possibility that an issue that is not the most pressing today can become the most pressing issue in the future if no new policy is implemented (for example, climate change). New questions arise in the presence of nonstationary preferences-for example, does a party give priority to an issue that is not especially pressing today to prevent it from becoming serious in the future or does it delay addressing the issue to make it urgent for the opposition party to tackle? We leave these interesting questions for future research. 


\section{Mathematical APPEndix}

\section{A. Proof of Proposition 1}

Suppose $\left(s_{1}^{*}, s_{2}^{*}, x^{*}, y^{*}\right)$ is a dynamically efficient outcome, where $s_{t}^{*}$ is the issue addressed in period $t, x^{*}$ is the policy implemented on issue $s_{1}^{*}$, and $y^{*}$ is the policy implemented on issue $s_{2}^{*}$. In what follows, we prove the proposition by contradiction.

First, consider the case in which $s_{1}^{*}=s^{\prime}$. If $s_{2}^{*}=s$, then the gain in player $i$ 's dynamic payoff from outcome $\left(s, s^{\prime}, x^{*}, y^{*}\right)$ is $2\left[v_{i}\left(x^{*}\right)-v_{i}(s)\right]+v_{i}\left(y^{*}\right)-v_{i}\left(s^{\prime}\right)$ and the gain in player $i$ 's dynamic payoff from outcome $\left(s^{\prime}, s, x^{*}, y^{*}\right)$ is $2\left[v_{i}\left(x^{*}\right)-\right.$ $\left.v_{i}\left(s^{\prime}\right)\right]+v_{i}\left(y^{*}\right)-v_{i}(s)$. Note that $2\left[v_{i}\left(x^{*}\right)-v_{i}(s)\right]+v_{i}\left(y^{*}\right)-v_{i}\left(s^{\prime}\right)-2\left[v_{i}\left(x^{*}\right)-\right.$ $\left.v_{i}\left(s^{\prime}\right)\right]-v_{i}\left(y^{*}\right)+v_{i}(s)=v_{i}\left(s^{\prime}\right)-v_{i}(s)$, which is strictly greater than zero for $i \in\{D, R\}$ since $s$ is more pressing than $s^{\prime}$ for both parties. It follows that the outcome $\left(s, s^{\prime}, x^{*}, y^{*}\right)$ Pareto dominates $\left(s^{\prime}, s, x^{*}, y^{*}\right)$, a contradiction. If $s_{2}^{*} \neq s$, then the outcome $\left(s, s_{2}^{*}, x^{*}, y^{*}\right)$ Pareto dominates $\left(s^{\prime}, s_{2}^{*}, x^{*}, y^{*}\right)$ since $v_{i}\left(x^{*}\right)-v_{i}(s)$ $>v_{i}\left(x^{*}\right)-v_{i}\left(s^{\prime}\right)$, a contradiction.

Next consider the case in which $s_{1}^{*} \neq s$ and $s_{2}^{*}=s^{\prime}$. Since $v_{i}(s)<v_{i}\left(s^{\prime}\right)$ for $i \in\{D, R\}$, we have $v_{i}\left(y^{*}\right)-v_{i}(s)>v_{i}\left(y^{*}\right)-v_{i}\left(s^{\prime}\right)$. It follows that the outcome $\left(s_{1}^{*}, s, x^{*}, y^{*}\right)$ Pareto dominates $\left(s_{1}^{*}, s^{\prime}, x^{*}, y^{*}\right)$, a contradiction.

Hence, in any dynamically Pareto efficient outcome, if issue $s^{\prime}$ is addressed, issue $s$ is addressed in period 1 .

\section{B. Proof of Proposition 2}

We show that if the incumbent's period 1 payoff is higher by addressing issue $s_{1}$ instead of addressing issue $s_{1}^{\prime}$, then its period 2 payoff is also higher if issue $s_{1}$ was addressed than if issue $s_{1}^{\prime}$ was addressed in period 1. Proposition 2 follows from this result.

Let $i$ denote the incumbent in both periods and let $a_{i}^{\pi}(s)$ be the policy that can be implemented by party $i$ that maximizes its static payoff if it addresses issue $s$ in power state $\pi$. Note that $a_{i}^{\pi}(s)$ does not depend on the time period.

Since party $i$ 's period 1 payoff is higher by addressing issue $s_{1}$ than by addressing issue $s_{1}^{\prime}$, we have $v_{i}\left(a_{i}^{\pi_{1}}\left(s_{1}\right)\right)+v_{i}\left(s_{1}^{\prime}\right) \geq v_{i}\left(a_{i}^{\pi_{1}}\left(s_{1}^{\prime}\right)\right)+v_{i}\left(s_{1}\right)$. Suppose if issue $s_{1}^{\prime}$ was addressed in period 1 , then the optimal issue to address in period 2 is issue $s_{2}$. Consider the following cases. (i) Suppose $s_{2} \neq s_{1}$. In this case, if issue $s_{1}$ was addressed in period 1, then the optimal issue to address in period 2 is either issue $s_{2}$ or issue $s_{1}^{\prime}$. If it is issue $s_{2}$, it follows immediately that party i's period 2 payoff is higher if issue $s_{1}$ instead of $s_{1}^{\prime}$ was addressed in period 1 . If it is issue $s_{1}^{\prime}$, since party $i$ 's period 1 payoff is higher by addressing $s_{1}$ instead of $s_{1}^{\prime}$, its period 2 payoff is also higher when $s_{1}$ is addressed in period 1 and $s_{1}^{\prime}$ is addressed in period 2 than when $s_{1}^{\prime}$ is addressed in period 1 and $s_{1}$ is addressed in period 2 . (ii) Suppose $s_{2}=s_{1}$. In this case, party i's period 2 payoff if issue $s_{1}$ was addressed in period 1 and issue $s_{1}^{\prime}$ is addressed in period 2 is the same as its period 2 payoff if issue $s_{1}^{\prime}$ was addressed in period 1 and issue $s_{2}=s_{1}$ is addressed in period 2. Since party $i$ achieves the highest period 2 payoff by addressing issue $s_{2}$ if issue $s_{1}^{\prime}$ was addressed in period 1, it follows that party $i$ 's period 2 payoff is higher if issue $s_{1}$ was addressed than if issue $s_{1}^{\prime}$ was addressed in period 1 . 


\section{Proof of Proposition 3}

To show part (i), note that when the incumbent is in strong power, it can move the policy on any issue to its ideal. Since the most pressing issue for party $i$ gives it the lowest status quo payoff, it follows immediately that in period 2, party $i$ achieves the highest payoff by addressing the most pressing issue for itself and moving the policy on that issue to its ideal.

To show part (ii), suppose party $D$ is in weak power in period 2 . Note that if party $D$ addresses a Republican issue, it moves the policy on that issue to its ideal $D$, and if party $D$ addresses a Democratic issue $s$, it moves the policy on that issue to $r(s)$. Let $\hat{s}$ be the issue that party $D$ addresses. If $\hat{s}$ is a Republican issue, then the difference in party $D$ 's period 2 payoff if it addresses issue $s_{R}$ and if it addresses issue $\hat{s}$ is $v_{D}(\hat{s})-v_{D}\left(s_{R}\right)$. Since $s_{R} \leq \hat{s}<D$ and $v_{D}(x)$ is increasing for $x<D$, addressing $s_{R}$ is better than addressing any other Republican issue. Similarly, if $\hat{s}$ is a Democratic issue, then the difference in party $D$ 's period 2 payoff if it addresses issue $s_{D}$ and if it addresses issue $\hat{s}$ is $v_{D}\left(r\left(s_{D}\right)\right)+v_{D}(\hat{s})-v_{D}(r(\hat{s}))-v_{D}\left(s_{D}\right)$. Since $D \leq r\left(s_{D}\right) \leq r(\hat{s})<\hat{s}<s_{D}$ and $v_{D}(x)$ is decreasing for $x \geq D$, it follows that addressing $s_{D}$ is better than addressing any other Democratic issue. Since party $D$ cannot change the status quo of a controversial issue when it is in weak power, it follows that it either addresses issue $s_{R}$ or issue $s_{D}$ if there is at least one Democratic issue and one Republican issue. In this case, since the difference in party $D$ 's period 2 payoff if it addresses issue $s_{R}$ and if it addresses issue $s_{D}$ is $v_{D}(D)+v_{D}\left(s_{D}\right)-$ $v_{D}(s)-v_{D}\left(r\left(s_{D}\right)\right)$, it follows that party $D$ addresses issue $s_{R}$ if and only if $v_{D}(D)+$ $v_{D}\left(s_{D}\right) \geq v_{D}(s)+v_{D}\left(r\left(s_{D}\right)\right)$. A similar argument proves the result if party $R$ is in weak power in period 2. Since party $D$ does not address a controversial issue when in weak power, if all noncontroversial issues are Democratic (Republican) issues, party $D$ addresses the most pressing Democratic (Republican) issue.

\section{Proof of Lemma 1}

Recall that we assume that the incumbent in period 1 is $D$. Consider $R_{i}$ with $i \geq 3$. In what follows, we show that addressing $R_{2}$ gives party $D$ a higher payoff than addressing $R_{i}$ in period 1 . If party $D$ addresses either $R_{2}$ or $R_{i}$, it moves the policy on that issue to its ideal $D$. Hence, the gain in payoff in period 1 to party $D$ from addressing $R_{2}$ instead of $R_{i}$ in period 1 is $v_{D}\left(R_{i}\right)-v_{D}\left(R_{2}\right)>0$. Note also that if either $R_{2}$ or $R_{i}$ is addressed in period 1, then both $R_{1}$ and $D_{1}$ are rolled over to period 2, and by Proposition 3, either party's choice in period 2 is not affected. Hence, it is strictly better for party $D$ to address $R_{2}$ instead of $R_{i}$ in period 1 . A similar argument shows that it is strictly better for party $D$ to address $D_{2}$ than any controversial issue or any $D_{i}$ with $i \geq 3$.

\section{E. Proof of Proposition 4}

Recall that we assume that party $D$ is the incumbent in period 1, i.e., $\pi_{1} \in\left\{S_{D}, W_{D}\right\}$. We prove the result by showing that addressing $R_{1}$ in period 1 results in a higher payoff in both periods for party $D$ than addressing $R_{2}$. For any 
$\pi_{1} \in\left\{S_{D}, W_{D}\right\}$, if party $D$ addresses $R_{1}$ or $R_{2}$, it moves the policy to its ideal $D$ on that issue. Hence, the difference in period 1 payoff to party $D$ between addressing $R_{1}$ and addressing $R_{2}$ is $v_{D}\left(R_{2}\right)-v_{D}\left(R_{1}\right)>0$. We next show that party $D$ 's period 2 payoff is also higher if it addresses issue $R_{1}$ instead of $R_{2}$ in the first period for any $\pi_{2} \in\left\{S_{D}, W_{D}, S_{R}, W_{R}\right\}$.

Since party $D$ 's period 1 payoff is higher by addressing $R_{1}$ instead of $R_{2}$ for any $\pi_{1} \in\left\{S_{D}, W_{D}\right\}$, by the argument in Proposition 2, party $D$ 's period 2 payoff is also higher if $R_{1}$ instead of $R_{2}$ was addressed in the first period if $\pi_{2}=S_{D}$ or if $\pi_{2}=W_{D}$. So it suffices to consider what happens if $\pi_{2}=S_{R}$ or if $\pi_{2}=W_{R}$.

(i) Suppose $\pi_{2}=S_{R}$. (a) If $v_{R}\left(R_{2}\right)<v_{R}\left(D_{1}\right)$, then $v_{R}\left(R_{1}\right)<v_{R}\left(D_{1}\right)$. In this case, if either $R_{1}$ or $R_{2}$ was addressed in period 1, party $R$ addresses the remaining Republican issue $\left(R_{2}\right.$ or $\left.R_{1}\right)$ by moving the policy to $R$. Hence, regardless of whether $R_{1}$ or $R_{2}$ was addressed in period 1 , party $D$ 's period 2 payoff is $v_{D}(D)+$ $v_{D}(R)+v_{D}\left(D_{1}\right)+v_{D}\left(D_{2}\right)$. (b) If $v_{R}\left(R_{1}\right)>v_{R}\left(D_{1}\right)$, then $v_{R}\left(R_{2}\right)>v_{R}\left(D_{1}\right)$. In this case, party $R$ addresses issue $D_{1}$ in period 2 regardless of whether issue $R_{1}$ or $R_{2}$ was addressed in period 1 , and the difference in period 2 payoff for party $D$ from addressing $R_{1}$ in the first period instead of $R_{2}$ is $v_{D}\left(R_{2}\right)-v_{D}\left(R_{1}\right)>0$. (c) Finally, if $v_{R}\left(R_{2}\right)>v_{R}\left(D_{1}\right)>v_{R}\left(R_{1}\right)$, then party $R$ addresses the Democratic issue $D_{1}$ if issue $R_{2}$ is rolled over to period 2, but addresses the Republican issue $R_{1}$ if issue $R_{1}$ is rolled over to period 2. In this case, party $D$ 's period 2 payoff is $v_{D}(D)+$ $v_{D}\left(R_{2}\right)+v_{D}\left(D_{2}\right)+v_{D}(R)$ if he addresses $R_{1}$ in period 1 , and is $v_{D}(R)+v_{D}(D)+$ $v_{D}\left(D_{2}\right)+v_{D}\left(D_{1}\right)$ if he addresses $R_{2}$ in period 1. Since $v_{R}\left(R_{2}\right)>v_{R}\left(D_{1}\right)$, by the single-crossing property, it is not possible to have $v_{D}\left(D_{1}\right)>v_{D}\left(R_{2}\right)$, and so party $D$ 's period 2 payoff is higher if $R_{1}$ instead of $R_{2}$ was addressed in period 1 .

(ii) Suppose $\pi_{2}=W_{R}$. Similar to case (i), if party $R$ addresses the remaining Republican issue or issue $D_{1}$ regardless of whether $R_{1}$ or $R_{2}$ was addressed in period 1, then party $D$ 's period 2 payoff is higher if $R_{1}$ instead of $R_{2}$ was addressed in period 1 . The remaining case is when party $R$ addresses issue $D_{1}$ if issue $R_{2}$ is rolled over to period 2 but addresses $R_{1}$ if $R_{1}$ is rolled over to period 2 . This happens if

$$
v_{R}\left(d\left(R_{2}\right)\right)+v_{R}\left(D_{1}\right) \leq v_{R}\left(R_{2}\right)+v_{R}(R)
$$

and

$$
v_{R}\left(d\left(R_{1}\right)\right)+v_{R}\left(D_{1}\right) \geq v_{R}\left(R_{1}\right)+v_{R}(R) .
$$

In this case, party $D$ 's period 2 payoff is $v_{D}(D)+v_{D}\left(R_{2}\right)+v_{D}\left(D_{2}\right)+v_{D}(R)$ if it addresses $R_{1}$ in period 1 , and $v_{D}\left(d\left(R_{1}\right)\right)+v_{D}(D)+v_{D}\left(D_{2}\right)+v_{D}\left(D_{1}\right)$ if it addresses $R_{2}$ in period 1. If $v_{D}\left(d\left(R_{1}\right)\right)=v_{D}\left(R_{1}\right)$, then $D$ 's period 2 payoff is higher if $R_{1}$ instead of $R_{2}$ was addressed in period 1 since $v_{D}\left(R_{2}\right)>v_{D}\left(R_{1}\right)$ and $v_{D}(R)$ $>v_{D}\left(D_{1}\right)$. If $v_{D}\left(d\left(R_{1}\right)\right) \neq v_{D}\left(R_{1}\right)$, then it must be the case that $v_{D}\left(d\left(R_{1}\right)\right)$ $=v_{D}(R)>v_{D}\left(R_{1}\right)$. In this case, the period 1 gain in payoff for party $D$ from addressing $R_{1}$ instead of $R_{2}$ is $v_{D}\left(R_{2}\right)-v_{D}\left(R_{1}\right)>0$, and the period 2 gain in payoff for party $D$ from addressing $R_{1}$ instead of $R_{2}$ is $v_{D}\left(R_{2}\right)-v_{D}\left(D_{1}\right)$. If $v_{D}\left(R_{2}\right)$ $\geq v_{D}\left(D_{1}\right)$, then $D$ is better off addressing $R_{1}$ in the first period, and the conclusion follows. Suppose instead that $v_{D}\left(R_{2}\right)<v_{D}\left(D_{1}\right)$. Since $v_{D}(R)>v_{D}\left(D_{1}\right)$, we 
have $v_{D}(R)>v_{D}\left(R_{2}\right)$, which implies that $v_{D}\left(d\left(R_{2}\right)\right)>v_{D}\left(R_{2}\right)$. It follows that $d\left(R_{2}\right)=R$, and since $R$ addresses issue $D_{1}$ if issue $R_{2}$ is rolled over, inequality (A1) implies that $v_{R}\left(D_{1}\right) \leq v_{R}\left(R_{2}\right)$. In this case, by the single-crossing property, we have $v_{D}\left(R_{2}\right)>v_{D}\left(D_{1}\right)$, and therefore $D$ 's period 2 payoff is higher if $R_{1}$ instead of $R_{2}$ was addressed in period 1 .

To summarize, party $D$ 's total payoff is higher by addressing $R_{1}$ than by addressing $R_{2}$ in period 1 for any $\pi_{2} \in\left\{S_{D}, W_{D}, S_{R}, W_{R}\right\}$. Hence, regardless of the power transition, party $D$ does not address $R_{2}$ in period 1 .

\section{F. Proof of Lemma 2}

Suppose party $D$ addresses issue $D_{2}$ in period 1 in equilibrium. Since party $D$ 's period 1 payoff is higher by addressing issue $D_{1}$ than issue $D_{2}$ in period 1 , it must be that its expected payoff in period 2 is higher by addressing issue $D_{2}$ instead of issue $D_{1}$ in period 1 . Since we assume that the incumbent's strength of power is the same in both periods, if party $D$ continues to be in power in period 2, its strength of power remains the same. In this case, by the argument in Proposition 2, party $D$ 's period 2 payoff is higher if it addresses issue $D_{1}$ instead of $D_{2}$ in period 1. Since party $D$ 's dynamic payoff is continuous in the distribution of the power state in period 2, it must be the case that party $R$ comes in power in period 2 with sufficiently high probability, and moreover, if party $R$ comes in to power in period 2, party $D$ 's period 2 payoff must be higher if it addresses issue $D_{2}$ instead of issue $D_{1}$ in period 1.

Suppose issue $D_{1}$ was addressed in period 1. By Proposition 3, if party $R$ is in power in period 2, it addresses either issue $R_{1}$ or $D_{2}$. Suppose party $R$ addresses issue $D_{2}$. Then it would address issue $D_{1}$ if issue $D_{2}$ was addressed in period 1 . That is, regardless of whether $D_{1}$ or $D_{2}$ was addressed in period 1 , party $R$ would address the remaining Democratic issue in period 2. Note that regardless of its strength of power, party $R$ moves the policy to its ideal if it addresses a Democratic issue. It follows that party $D$ 's period 2 payoff is higher if it addresses issue $D_{1}$ instead of issue $D_{2}$ in period 1 , a contradiction. Hence, it must be the case that party $R$ addresses issue $R_{1}$ if issue $D_{1}$ was addressed in period 1 .

Suppose issue $D_{2}$ was addressed in period 1. By Proposition 3, if party $R$ is in power in period 2, it addresses either issue $R_{1}$ or $D_{1}$. If party $R$ addresses issue $R_{1}$, then it would also address issue $R_{1}$ if issue $D_{1}$ was addressed in period 1, which implies that party $D$ 's period 2 payoff is higher if it addresses issue $D_{1}$ instead of issue $D_{2}$ in period 1 , a contradiction. Hence, it must be the case that party $R$ addresses issue $D_{1}$ if issue $D_{2}$ was addressed in period 1 .

\section{G. Proof of Proposition 5}

By Proposition 4, party $D$ does not address issue $R_{2}$ in period 1 in equilibrium. Next, consider the choice between issues $D_{1}$ and $D_{2}$ for party $D$ in period 1 . Suppose party $R$ comes in to power in period 2. Since $v_{R}\left(R_{1}\right)<v_{R}\left(D_{1}\right)<v_{R}\left(D_{2}\right)$, it follows that regardless of whether $D_{1}$ or $D_{2}$ was addressed in period 1 , party $R$ addresses issue $R_{1}$ in period 2. By Lemma 2, party $D$ does not address issue $D_{2}$ in period 1 . 
Under partisan preferences, $v_{D}\left(D_{1}\right)<v_{D}\left(R_{1}\right)$, implying that party $D$ 's period 1 payoff is strictly higher by addressing issue $D_{1}$ instead of issue $R_{1}$. If party $D$ is in power in period 2, then its period 2 payoff is higher if it addresses issue $D_{1}$ instead of issue $R_{1}$ in period 1 by the argument in Propostion 2 . We next show that party $D$ 's period 2 payoff is weakly higher if it addresses issue $D_{1}$ instead of $R_{1}$ in period 1 when party $R$ is in power in period 2. If party $D$ addresses $D_{1}$ in period 1 , then, since $v_{R}\left(R_{1}\right)<v_{R}\left(D_{1}\right)<v_{R}\left(D_{2}\right)$, party $R$ addresses issue $R_{1}$ in period 2 and party $D$ 's period 2 payoff is

$$
v_{D}(R)+v_{D}\left(R_{2}\right)+v_{D}\left(D_{2}\right)+v_{D}(D) .
$$

If party $D$ addresses issue $R_{1}$ in period 1, then we have either (i) party $R$ addresses issue $D_{1}$ in period 2, which happens if $v_{R}\left(D_{1}\right) \leq v_{R}\left(R_{2}\right)$, or (ii) party $R$ addresses issue $R_{2}$ in period 2, which happens if $v_{R}\left(R_{2}\right)<v_{R}\left(D_{1}\right)$. We consider the two cases below:

(i) If party $R$ addresses $D_{1}$ in period 2, then party $D$ 's period 2 payoff is

$$
v_{D}(D)+v_{D}\left(R_{2}\right)+v_{D}\left(D_{2}\right)+v_{D}(R) .
$$

In this case, party $D$ 's period 2 payoff if it addresses $D_{1}$ and if it addresses $R_{1}$ in period 1 are the same.

(ii) If party $R$ addresses $R_{2}$ in period 2, then party $D$ 's period 2 payoff is

$$
v_{D}(D)+v_{D}(R)+v_{D}\left(D_{2}\right)+v_{D}\left(D_{1}\right) \text {. }
$$

In this case, the difference between party $D$ 's period 2 payoff if it addresses $D_{1}$ and if it addresses $R_{1}$ in period 1 is $v_{D}\left(R_{2}\right)-v_{D}\left(D_{1}\right)>0$.

In both cases, party $D$ 's period 2 payoff is weakly higher if it addresses issue $D_{1}$ instead of $R_{1}$ in period 1 . Hence, party $D$ addresses issue $D_{1}$ in period 1 .

\section{H. Proof of Proposition 6}

We first prove part (i). We establish the result under the assumption that party $R$ comes in to power in period 2 with probability 1 and

$$
v_{R}\left(d\left(R_{1}\right)\right)+v_{R}\left(D_{1}\right)<v_{R}\left(R_{1}\right)+v_{R}(R)<v_{R}\left(d\left(R_{1}\right)\right)+v_{R}\left(D_{2}\right) .
$$

When $R$ comes in to power in period 2, then it addresses $R_{1}$ if $D_{1}$ was addressed in period 1 , and it addresses $D_{1}$ if $D_{2}$ or $R_{1}$ was addressed in period 1 .

If party $D$ addresses issue $D_{1}$ in period 1 , then its payoff in period 1 is

$$
v_{D}\left(R_{1}\right)+v_{D}\left(R_{2}\right)+v_{D}\left(D_{2}\right)+v_{D}\left(r\left(D_{1}\right)\right),
$$


and its period 2 payoff is

$$
v_{D}\left(d\left(R_{1}\right)\right)+v_{D}\left(R_{2}\right)+v_{D}\left(D_{2}\right)+v_{D}\left(r\left(D_{1}\right)\right) .
$$

If party $D$ addresses issue $D_{2}$ in period 1 , then its payoff in period 1 is

$$
v_{D}\left(R_{1}\right)+v_{D}\left(R_{2}\right)+v_{D}\left(r\left(D_{2}\right)\right)+v_{D}\left(D_{1}\right)
$$

and its period 2 payoff is

$$
v_{D}\left(R_{1}\right)+v_{D}\left(R_{2}\right)+v_{D}\left(r\left(D_{2}\right)\right)+v_{D}(R) .
$$

If party $D$ addresses issue $R_{1}$ in period 1 , then its payoff in period 1 is

$$
v_{D}(D)+v_{D}\left(R_{2}\right)+v_{D}\left(D_{2}\right)+v_{D}\left(D_{1}\right)
$$

and its second period payoff is

$$
v_{D}(D)+v_{D}\left(R_{2}\right)+v_{D}\left(D_{2}\right)+v_{D}(R) .
$$

It follows that party $D$ prefers addressing $D_{2}$ to addressing $D_{1}$ and $R_{1}$ in the first period if

$$
\begin{aligned}
2 v_{D}\left(r\left(D_{2}\right)\right)+v_{D}\left(D_{1}\right)+v_{D}(R)+v_{D}\left(R_{1}\right) \\
\quad>2 v_{D}\left(D_{2}\right)+2 v_{D}\left(r\left(D_{1}\right)\right)+v_{D}\left(d\left(R_{1}\right)\right)
\end{aligned}
$$

and

$$
2 v_{D}\left(R_{1}\right)+2 v_{D}\left(r\left(D_{2}\right)\right)>2 v_{D}(D)+2 v_{D}\left(D_{2}\right)
$$

To sum up, if conditions (A3), (A4), and (A5) are satisfied, then party $D$ addresses $D_{2}$ in period 1. Since these conditions can be satisfied under partisan preferences, party $D$ may address $D_{2}$ in period 1 in equilibrium. Under strongly partisan preferences, however, party $R$ addresses issue $R_{1}$ regardless of whether $D_{1}$ or $D_{2}$ was addressed in period 1 . Then, by Lemma 2, party $D$ does not address issue $D_{2}$ in period 1 in equilibrium under strongly partisan preferences.

We now prove part (ii). We establish the result under the assumption that party $R$ comes in to power in period 2 with probability 1 and $v_{R}\left(R_{2}\right)+v_{R}(R)$ $<v_{R}\left(D_{1}\right)+v_{R}\left(d\left(R_{2}\right)\right)$. 
When $R$ comes in to power in period 2 , then it addresses $R_{1}$ by moving it to $d\left(R_{1}\right)$ if $D_{1}$ was addressed in period 1 , and it addresses $D_{1}$ if $R_{1}$ was addressed in period 1 .

If party $D$ addresses issue $D_{1}$ in period 1 , then its period 1 payoff is $v_{D}\left(R_{1}\right)+$ $v_{D}\left(R_{2}\right)+v_{D}\left(D_{2}\right)+v_{D}\left(r\left(D_{1}\right)\right)$, and its period 2 payoff is $v_{D}\left(d\left(R_{1}\right)\right)+v_{D}\left(R_{2}\right)+$ $v_{D}\left(D_{2}\right)+v_{D}\left(r\left(D_{1}\right)\right)$.

If party $D$ addresses issue $R_{1}$ in period 1 , then its period 1 payoff is $v_{D}(D)+$ $v_{D}\left(R_{2}\right)+v_{D}\left(D_{2}\right)+v_{D}\left(D_{1}\right)$, and its period 2 payoff is $v_{D}(D)+v_{D}\left(R_{2}\right)+v_{D}\left(D_{2}\right)+$ $v_{D}(R)$.

Hence, the difference between party $D$ 's dynamic payoff if it addresses issue $D_{1}$ and if it addresses issue $R_{1}$ in period 1 is

$$
v_{D}\left(R_{1}\right)+v_{D}\left(d\left(R_{1}\right)\right)+2\left[v_{D}\left(r\left(D_{1}\right)\right)-v_{D}(D)-v_{D}\left(D_{1}\right)\right]+v_{D}\left(D_{1}\right)-v_{D}(R) .
$$

It follows that if $v_{D}(R)-v_{D}\left(D_{1}\right)>v_{D}\left(R_{1}\right)+v_{D}\left(d\left(R_{1}\right)\right)+2\left[v_{D}\left(r\left(D_{1}\right)\right)-\right.$ $\left.v_{D}(D)-v_{D}\left(D_{1}\right)\right]$, which is still possible under strongly partisan preferences, party $D$ addresses issue $R_{1}$ in period 1 in equilibrium.

\section{Proof of Proposition 7}

We prove part (i) by considering the cases when $\pi_{1}=S_{D}$ and when $\pi_{1}=W_{D}$. (a) Suppose $\pi_{1}=S_{D}$. Then party $D$ 's period 1 payoff is higher by addressing issue $D_{1}$ instead of addressing issue $D_{2}$. If $\pi_{2}=S_{D}$, then, by the argument in Proposition 2, its period 2 payoff is also higher if it addresses $D_{1}$ than if it addresses $D_{2}$ in period 1. If $\pi_{2}=S_{R}$, then, since preferences are partisan, party $R$ addresses issue $R_{1}$ regardless of whether $D_{1}$ or $D_{2}$ was addressed in period 1 . In this case, party $D$ 's period 2 payoff is again higher if it addresses $D_{1}$ than if it addresses $D_{2}$ in period 1 . Since party $D$ 's dynamic payoff is higher by addressing issue $D_{1}$ than issue $D_{2}$ in period 1 when the incumbent in period 2 will be in strong power, continuity of the expected payoff in power transition probabilities implies that if it is sufficiently likely that the incumbent will be in strong power in period 2, then party $D$ does not give priority to the less pressing Democratic issue $D_{2}$ in period 1 . (b) Suppose $\pi_{1}=W_{D}$. Then, party $D$ 's period 1 payoff is again higher by addressing issue $D_{1}$ instead of addressing issue $D_{2}$. As shown in part (a), if $\pi_{2}=S_{R}$, then party $D$ 's period 2 payoff is higher if it addresses $D_{1}$ than if it addresses $D_{2}$ in period 1 . So we only need to consider the case when $\pi_{2}=S_{D}$. If party $D$ addresses issue $D_{2}$ in period 1 , then it will address issue $D_{1}$ in period 2 when it comes in strong power. Hence, the total gain in its payoff is $2\left[v_{D}\left(r\left(D_{2}\right)\right)-v_{D}\left(D_{2}\right)\right]+v_{D}(D)-$ $v_{D}\left(D_{1}\right)$. If party $D$ addresses issue $D_{1}$ in period 1 , then it will address either issue $D_{2}$ or issue $R_{1}$ in period 2 when it comes in to strong power. Hence, the total gain in its payoff is

$$
\begin{aligned}
& 2\left[v_{D}\left(r\left(D_{1}\right)\right)-v_{D}\left(D_{1}\right)\right]+\max \left\{v_{D}(D)-v_{D}\left(D_{2}\right), v_{D}(D)-v_{D}\left(R_{1}\right)\right\} \\
& \geq 2\left[v_{D}\left(r\left(D_{1}\right)\right)-v_{D}\left(D_{1}\right)\right]+v_{D}(D)-v_{D}\left(D_{2}\right) .
\end{aligned}
$$


Since

$$
\begin{aligned}
2\left[v_{D}\left(r\left(D_{1}\right)\right)-v_{D}\left(D_{1}\right)\right]+v_{D}(D)-v_{D}\left(D_{2}\right) \\
\quad-\left[2\left[v_{D}\left(r\left(D_{2}\right)\right)-v_{D}\left(D_{2}\right)\right]+v_{D}(D)-v_{D}\left(D_{1}\right)\right] \\
\quad=2\left[v_{D}\left(r\left(D_{1}\right)\right)-v_{D}\left(r\left(D_{2}\right)\right)\right]+v_{D}\left(D_{2}\right)-v_{D}\left(D_{1}\right)>0,
\end{aligned}
$$

it follows that party $D$ 's dynamic payoff is higher by addressing issue $D_{1}$ than issue $D_{2}$ in period 1 in this case too. Continuity implies that if it is sufficiently likely that the incumbent will be in strong power in period 2, then party $D$ does not give priority to the less pressing Democratic issue $D_{2}$ in period 1 .

We prove part (ii) also by considering the cases when $\pi_{1}=W_{D}$ and when $\pi_{1}=S_{D}$. (a) Suppose $\pi_{1}=W_{D}$. As shown in Proposition 6, party $D$ may give priority to issue $D_{2}$ when the incumbent in period 2 will be in weak power. By continuity, party $D$ may give priority to issue $D_{2}$ when it is sufficiently likely that the incumbent in period 2 will be in weak power. (b) Suppose $\pi_{1}=S_{D}$. First, consider the case when $\pi_{2}=W_{R}$. Suppose (A3) holds, which implies that party $R$ addresses $R_{1}$ if $D_{1}$ was addressed in period 1 and addresses $D_{1}$ if $D_{2}$ or $R_{1}$ was addressed in period 1. If party $D$ addresses issue $D_{2}$ in period 1 , then its total gain in payoff is $2\left[v_{D}(D)-v_{D}\left(D_{2}\right)\right]+v_{D}(R)-v_{D}\left(D_{1}\right)$. If party $D$ addresses issue $D_{1}$ in period 1 , then its total gain in payoff is $2\left[v_{D}(D)-v_{D}\left(D_{1}\right)\right]+v_{D}\left(d\left(R_{1}\right)\right)-v_{D}\left(R_{1}\right)$. If party $D$ addresses issue $R_{1}$ in period 1 , then party $R$ will address issue $D_{1}$ in period 2 and party $D$ 's total gain in payoff is $2\left[v_{D}(D)-v_{D}\left(R_{1}\right)\right]+v_{D}(R)-v_{D}\left(D_{1}\right)$. It follows that party $D$ prefers to address $D_{2}$ instead of $D_{1}$ or $R_{1}$ in period 1 if

$$
v_{D}(R)-v_{D}\left(D_{1}\right)+v_{D}\left(R_{1}\right)-v_{D}\left(d\left(R_{1}\right)\right)+2\left[v_{D}\left(D_{1}\right)-v_{D}\left(D_{2}\right)\right]>0
$$

and $v_{D}\left(D_{2}\right)<v_{D}\left(R_{1}\right)$.

We next consider the case when $\pi_{2}=W_{D}$ under the assumption that

$$
v_{D}\left(r\left(D_{2}\right)\right)-v_{D}\left(D_{2}\right)>v_{D}(D)-v_{D}\left(R_{1}\right)
$$

Then party $D$ addresses a Democratic issue in period 2. If party $D$ addresses issue $D_{1}$ in period 1 , then it will address issue $D_{2}$ in period 2 , and its total gain in payoff is $2\left[v_{D}(D)-v_{D}\left(D_{1}\right)\right]+v_{D}\left(r\left(D_{2}\right)\right)-v_{D}\left(D_{2}\right)$. If party $D$ addresses issue $D_{2}$ in period 1 , then it will address issue $D_{1}$ in period 2 , and its total gain in payoff is $2\left[v_{D}(D)-v_{D}\left(D_{2}\right)\right]+v_{D}\left(r\left(D_{1}\right)\right)-v_{D}\left(D_{1}\right)$. If party $D$ addresses issue $R_{1}$ in period 1 , then it will address issue $D_{1}$ in period 2, and its total gain in payoff is $2\left[v_{D}(D)-v_{D}\left(R_{1}\right)\right]+v_{D}\left(r\left(D_{1}\right)\right)-v_{D}\left(D_{1}\right)$. Given $(\mathrm{A} 7)$, party $D$ prefers to address issue $D_{2}$ instead of issue $R_{1}$ in period 1. Also, if

$$
v_{D}\left(r\left(D_{1}\right)\right)-v_{D}\left(r\left(D_{2}\right)\right)+v_{D}\left(D_{1}\right)-v_{D}\left(D_{2}\right)>0,
$$


then party $D$ prefers to address issue $D_{2}$ instead of issue $D_{1}$ in period 1 . To summarize, if (A3), (A6), (A7), (A8), and $v_{D}\left(D_{2}\right)<v_{D}\left(R_{1}\right)$ hold, then party $D$ gives priority to issue $D_{2}$ if the incumbent is in weak power in period 2. By continuity, the result holds if it is sufficiently likely that the incumbent is in weak power in period 2.

\section{J. Proof of Proposition 8}

If party $D$ addresses issue $D_{1}$ in period 1 , then, since $\pi_{1}=W_{D}$, party $D$ moves the policy on issue $D_{1}$ to $r\left(D_{1}\right)$. Suppose $v_{D}\left(R_{1}\right)>v_{D}\left(D_{2}\right)$, which implies that party $D$ addresses $D_{2}$ in period 2 since $\pi_{2}=S_{D}$. In this case, party $D$ 's total gain in payoff is $2\left[v_{D}\left(r\left(D_{1}\right)\right)-v_{D}\left(D_{1}\right)\right]+v_{D}(D)-v_{D}\left(D_{2}\right)$.

If party $D$ addresses issue $R_{1}$ in period 1 , then party $D$ moves the policy on issue $R_{1}$ to $D$. Since preferences are strongly partisan and $\pi_{2}=S_{D}$, party $D$ addresses issue $D_{1}$ in period 2. In this case, party $D$ 's total gain in payoff is $2\left[v_{D}(D)-v_{D}\left(R_{1}\right)\right]+v_{D}(D)-v_{D}\left(D_{1}\right)$.

If follows that if $v_{D}\left(R_{1}\right)>v_{D}\left(D_{2}\right)$ and

$$
2\left[\left(v_{D}(D)-v_{D}\left(R_{1}\right)\right)-\left(v_{D}\left(r\left(D_{1}\right)\right)-v_{D}\left(D_{1}\right)\right)\right]>v_{D}\left(D_{1}\right)-v_{D}\left(D_{2}\right),
$$

then party $D$ 's payoff is higher by addressing issue $R_{1}$ instead of addressing issue $D_{1}$ or $D_{2}$ in period 1 . Under strongly partisan preferences, $\left(v_{D}(D)-v_{D}\left(R_{1}\right)\right)-$ $\left(v_{D}\left(r\left(D_{1}\right)\right)-v_{D}\left(D_{1}\right)\right)<0$, but since $v_{D}\left(D_{1}\right)-v_{D}\left(D_{2}\right)<0$, condition (A9) can still be satisfied. It is also straightforward to show that party $D$ does not give priority to issue $D_{2}$. Hence, party $D$ may address issue $R_{1}$ in period 1 in equilibrium even under strongly partisan preferences.

\section{REFERENCES}

-Acemoglu, Daron, Mikhail Golosov, and Aleh Tsyvinski. 2011. "Power fluctuations and political economy." Journal of Economic Theory 146 (3): 1009-41.

Anton, James, and Dennis Yao. 2012. "Delay as Agenda Setting." Economic Research Initiatives at Duke (ERID) Working Paper 135.

-Aragonès, Enriqueta, Micael Castanheira, and Marco Giani. 2015. "Electoral Competition through Issue Selection." American Journal of Political Science 59 (1): 71-90.

-Azzimonti, Marina. 2011. "Barriers to Investment in Polarized Societies." American Economic Review 101 (5): 2182-2204.

Banks, J. S. 1985. "Sophisticated voting outcomes and agenda control." Social Choice and Welfare 1 (4): 295-306.

- Barberà, Salvador, and Anke Gerber. 2017. “Sequential Voting and Agenda Manipulation.” Theoretical Economics 12 (1): 211-47.

Black, Duncan. 1958. The Theory of Committees and Elections. Cambridge: Cambridge University Press.

- Bowen, T. Renee, Ying Chen, and Hülya Eraslan. 2014. "Mandatory versus Discretionary Spending: The Status Quo Effect." American Economic Review 104 (10): 2941-74.

Buisseret, Peter, and Dan Bernhardt. 2015. "Dynamics of Policymaking: Stepping Back to Leap Forward, Stepping Forward to Keep Back." http://fbe.usc.edu/seminars/papers/AE_9-18-15_ BUISSERET.pdf.

Callander, Steven, and Patrick Hummel. 2014. "Preemptive Policy Experimentation." Econometrica 4 (82): 1509-28.

Chen, M. Keith. 2002. "Agendas in Multi-Issue Bargaining: When to Sweat the Small Stuff." Unpublished. 
Chen, Ying, and Hülya Eraslan. 2013. "Informational loss in bundled bargaining." Journal of Theoretical Politics 25 (3): 338-62.

Chen, Ying, and Hülya Eraslan. 2014. "Rhetoric in legislative bargaining with asymmetric information." Theoretical Economics 9 (2): 483-513.

Copič, Jernej, and Jonathan N. Katz. 2012. "Auctioning off the Agenda: Bargaining in Legislatures with Endogeneous Scheduling." California Institute of Technology Social Science Working Paper 1266R.

Dellis, Arnaud. 2009. "The Salient Issue of Issue Salience.” Journal of Public Economic Theory 11 (2): 203-31.

DDagu, Tiberiu, and Xiaochen Fan. 2016. "An Agenda-Setting Theory of Electoral Competition." Journal of Politics 78 (4): 1117-83.

Duggan, J., and C. Martinelli. 2011. "A Spatial Theory of Media Slant and Voter Choice." Review of Economic Studies 78 (2): 640-66.

Egorov, Georgy. 2012. "Single-Issue Campaigns and Multidimensional Politics.” http://economics.mit. edu/files/8506.

Fershtman, Chaim. 1990. "The importance of the agenda in bargaining." Games and Economic Behavior 2 (3): 224-38.

Glazer, Amihai, and Susanne Lohmann. 1999. "Setting the agenda: Electoral competition, commitment of policy, and issue salience." Public Choice 99 (3): 377-94.

-Holian, David B. 2004. "HE'S STEALING MY ISSUES! Clinton's Crime Rhetoric and the Dynamics of Issue Ownership." Political Behavior 26 (2): 95-124.

-In, Younghwan, and Roberto Serrano. 2004. "Agenda restrictions in multi-issue bargaining." Journal of Economic Behavior and Organization 53 (3): 385-99.

-Inderst, Roman. 2000. "Multi-issue Bargaining with Endogenous Agenda." Games and Economic Behavior 30 (1): 64-82.

-Jackson, Matthew O., and Boaz Moselle. 2002. "Coalition and Party Formation in a Legislative Voting Game.” Journal of Economic Theory 103 (1): 49-87.

Kingdon, John W. 1984. Agendas, Alternatives and Public Policies. Boston: Little, Brown and Company.

Lang, Kevin, and Robert W. Rosenthal. 2001. "Bargaining Piecemeal or All At Once?" Economic Journal 111 (473): 526-40.

McCombs, Maxwell E., and Donald L. Shaw. 1972. "The Agenda-Setting Function of Mass Media." Public Opinion Quarterly 36 (2): 176-87.

McKelvey, Richard D. 1976. "Intransitivities in multidimensional voting models and some implications for agenda control." Journal of Economic Theory 12 (3): 472-82.

Morris, Dick. 2002. Power Plays: Win or Lose-How History's Great Political Leaders Play the Game. New York: ReganBooks.

Persson, Torsten, and Lars E. O. Svensson. 1989. "Why a Stubborn Conservative Would Run a Deficit: Policy with Time-Inconsistent Preferences." Quarterly Journal of Economics 104 (2): 325-45.

Petrocik, John R. 1996. "Issue Ownership in Presidential Elections, with a 1980 Case Study." American Journal of Political Science 40 (3): 825-50.

Plott, Charles R., and Michael E. Levine. 1978. "A Model of Agenda Influence on Committee Decisions." American Economic Review 68 (1): 146-60.

Romer, Thomas, and Howard Rosenthal. 1978. "Political resource allocation, controlled agendas, and the status quo." Public Choice 33 (4): 27-43.

Romer, Thomas, and Howard Rosenthal. 1979. "Bureaucrats versus Voters: On the Political Economy of Resource Allocation by Direct Democracy." Quarterly Journal of Economics 93 (4): 563-87.

Tabellini, Guido, and Alberto Alesina. 1990. "Voting on the Budget Deficit." American Economic Review 80 (1): 37-49. 